\title{
O uso de pseudosseções em Petrologia Metamórfica: conceitos básicos e aplicações, com ênfase em pelitos
}

The use of pseudosections in metamorphic petrology: basic concepts and applications, with emphasis on pelites

\author{
Rafaela Machado Gengo ${ }^{1}$ (D), Caio Arthur Santos ${ }^{1}$ (D), Renato Moraes ${ }^{1}$ (D), Gergely Andres Julio Szabó ${ }^{1}$ (D) \\ ${ }^{1}$ Universidade de São Paulo - USP, Instituto de Geociências, Rua do Lago, 562, Cidade Universitária, CEP: 05508-080, São \\ Paulo, SP, BR (rafaela.gengo@alumni.usp.br; caio.santos@usp.br; rmoraes@usp.br; gajszabo@usp.br)
}

Recebido em 24 de maio de 2021; aceito em 17 de novembro de 2021.

\begin{abstract}
Resumo
O uso de pseudosseções em trabalhos voltados para Petrologia Metamórfica tem se tornado cada vez mais comum nos últimos 20 anos em razão de uma série de fatores, entre eles o avanço das técnicas de análise química mineral usando microssonda eletrônica e laser ablation acoplado à ICP-MS, além do refinamento no tratamento dos dados isotópicos em fases acessórias, tais como monazita e zircão, e, principalmente, o aperfeiçoamento dos softwares disponíveis para a sua construção. A cada ano são lançadas novas atualizações desses softwares; no entanto, bibliografias básicas que contemplem os aspectos teórico-práticos sobre as pseudosseções são escassas, sobretudo em língua portuguesa. Esta contribuição visou sintetizar esses aspectos, que são necessários para aqueles que desejam se aprofundar em Petrologia Metamórfica. Aqui são apresentados alguns princípios básicos de diagramas de fase, no geral, e pseudosseções, em particular, e são discutidos os primeiros passos de sua construção. Também são tratados aspectos topológicos de pseudosseções em diferentes sistemas químicos, para exemplificar as diferenças e as semelhanças que ocorrem.
\end{abstract}

Palavras-chave: Grades petrogenéticas; Termodinâmica; Modelagem metamórfica; Metapelitos.

\begin{abstract}
The use of pseudosections in Metamorphic Petrology publications has become more common in the last 20 years due to a variety of factors, such as the advance of mineral chemistry analysis techniques using electron microprobe and laser ablation coupled with an inductively coupled plasma mass spectrometry; refinement in the treatment of isotopic data from accessory phases, such as monazite and zircon; and, mainly, improvements in software used for pseudosection calculation. Each year new updates of such software are released, but basic bibliography that contemplates the theory and practice of pseudosection calculation is rare, especially in Portuguese. This contribution aims to synthesize these aspects, which are necessary for those who wish to delve into Metamorphic Petrology. Here we present some basic principles of phase diagrams in general, and pseudosections in particular, and discuss the first steps for the construction of pseudosections. We also consider topological aspects of pseudosections in different chemical systems to exemplify the differences and similarities that occur.
\end{abstract}

Keywords: Petrogenetic grids; Thermodynamics; Metamorphic modelling; Metapelites. 


\section{INTRODUÇÃO}

A termodinâmica tem sido usada desde o início do século $\mathrm{XX}$ para estimar as condições nas quais as rochas ígneas e metamórficas se formaram, estando assim ligada à definição das fácies metamórficas (Eskola, 1939; Spear et al., 2016; Brown e Johnson, 2018). A partir do final dos anos 1970, o desenvolvimento das bases de dados termodinâmicos internamente consistentes (Helgeson et al., 1978; Holland e Powell, 1985; Berman, 1988) permitiu a utilização de métodos multiequilíbrio e a construção de diversos tipos de diagramas de fase (Spear e Cheney, 1989; Powell e Holland, 1988, 1990). Esses métodos se tornaram comuns na Petrologia Metamórfica e, nos últimos 20 anos, os diagramas de estabilidade de associações minerais, conhecidos como pseudosseções, tornaram-se padrão na literatura internacional (Powell et al., 1998; Powell e Holland, 2008; Spear et al., 2016; Lanari e Duesterhoeft, 2019), de modo que saber interpretá-los e compreender suas aplicações se tornou fundamental para aqueles que desejam se aprofundar em Petrologia Metamórfica.

Nesta contribuição, apresentam-se os conceitos básicos sobre pseudosseções, desde construção e interpretação até os aspectos práticos da abordagem, desejáveis para aqueles que pretendem aplicar essa ferramenta para contribuir com o entendimento dos modelos geotectônicos, tal como apresentado por Reno et al. (2009), López-Carmona et al. (2013), Wernert et al. (2016), Tedeschi et al. (2017), Fumes et al. (2021), Motta et al. (2021), entre outros.

Todas as abreviações minerais utilizadas estão de acordo com Whitney e Evans (2010).

\section{ALGUNS CONCEITOS TERMODINÂMICOS}

Nesta seção, relembra-se de forma simplificada alguns conceitos e termos que serão importantes nas discussões subsequentes. Para um tratamento mais completo, recomendam-se ao leitor textos básicos de termodinâmica do equilíbrio (e.g. Ball, 2005; Atkins e Paula, 2018) e a própria literatura básica de Petrologia Metamórfica (e.g. Zen, 1966; Powell, 1978; Spear, 1993; Will, 1998; Candia et al., 2003; Philpotts e Ague, 2009). Este trabalho tem como função servir como ponte para o entendimento de textos avançados de modelamento termodinâmico, sejam textos introdutórios (Will, 1998) ou de pesquisa (e.g. White e Powell, 2010; Santos et al., 2021; Pavan et al., 2021a, 2021b).

Sistema é a porção separada do universo que se deseja investigar. Um sistema é dito isolado quando não troca nem matéria nem energia com o ambiente externo; fechado quando troca energia, mas não matéria; e aberto quando troca matéria e energia. $\mathrm{O}$ sistema corresponde à rocha metamórfica, porém isso não é tão simples, pois geralmente assume-se a hipótese, ainda que de forma implícita, de um sistema semiaberto, no qual apenas fases fluidas, principalmente $\mathrm{H}_{2} \mathrm{O}$ e $\mathrm{CO}_{2}$, são trocadas com o meio e que o resto da composição da rocha permanece essencialmente inalterado.

Fases (P) são porções fisicamente distintas e quimicamente homogêneas dentro de um sistema. Em Petrologia Metamórfica, as fases são os minerais mais os fluidos que se considera que estiveram presentes na rocha durante $o$ metamorfismo. Em casos extremos de temperatura, a presença de fundido silicático também é considerada como uma fase. Componentes (C) são os entes químicos utilizados para descrever a variação química do sistema. No caso, os componentes são geralmente representados na forma de óxidos $\left(\mathrm{SiO}_{2}, \mathrm{Al}_{2} \mathrm{O}_{3}\right.$ etc.). No jargão da Petrologia, é comum utilizar "sistema" (ou sistema químico) para se referir ao conjunto de componentes que está sendo considerado e, dependendo do problema estudado, pode-se escolher um sistema menor, com menor número de componentes, ou maior e mais abrangente, que representa de forma mais fidedigna a rocha estudada, com um número maior de componentes.

As variáveis termodinâmicas são usadas para descrever o estado do sistema, incluindo variáveis intensivas, que independem da massa (pressão, temperatura, potencial químico, fração molar de $\mathrm{CO}_{2}$ na fase fluida), e extensivas, que dependem da quantidade (volume, energia interna, entropia, entalpia, energia livre de Gibbs). Entre essas, as mais importantes são a pressão e a temperatura, que normalmente são as variáveis que se deseja determinar, e a energia livre de Gibbs, função que é minimizada quando o sistema se encontra em equilíbrio químico, o qual é o estado em que não há gradientes de pressão, temperatura ou potencial químico entre as diferentes partes do sistema (Spear, 1993; Philpotts e Ague, 2009).

A Regra das Fases de Gibbs estabelece o número de graus de liberdade ou a variância (F) de um sistema que esteja em equilíbrio. A variância se relaciona com o número de fases $(\mathrm{P})$ e de componentes (C) por meio da Equação 1:

$F=C-P+2$

Nessa formulação, são consideradas duas variáveis intensivas, indicadas pelo número 2 na equação (para a dedução da Regra das Fases para duas variáveis, ver, por exemplo, Candia et al. (2003), capítulo 2). Isso permite aplicar a fórmula para qualquer diagrama de fases que correlacione duas variáveis por vez, normalmente $P$ x $T$. Nesses diagramas, a variância $=0$ define uma condição de equilíbrio rigidamente estabelecida, em que nenhuma das variáveis pode ser modificada sob pena de alterar o equilíbrio, que ocorre entre o número máximo de fases, definido pela fórmula da Regra de Fases. Essa condição define um ponto invariante no diagrama, ao redor do qual se dispõem as linhas 
ou curvas univariantes, com variância $=1$. Nesse caso, $o$ equilíbrio pode ser mantido se uma das variáveis for alterada, contanto que a outra acompanhe, mantendo as condições definidas em cima da linha. Quando as reações são do tipo sólido-sólido, sem envolver fase fluida, essas linhas são retas; quando há participação de fase fluida, serão curvas no campo $P$ x $T$.

As linhas ou curvas univariantes representam as reações que separam os campos divariantes, com variância $=2$, para os quais as paragêneses (associações minerais em equilíbrio) são definidas. Nos campos divariantes, qualquer uma das variáveis pode ser livremente modificada, independentemente da outra, contanto que as condições se mantenham dentro do campo em questão. O número de linhas univariantes ao redor de um ponto invariante pode ser obtido pelas Regras de Schreinemakers, que determinam que o número de linhas seja igual a $\mathrm{C}+2$ e que o ângulo entre essas linhas não exceda $180^{\circ}$. Essas são as regras básicas que descrevem como a topologia das linhas ou curvas univariantes em torno dos pontos univariantes em um diagrama de fases é estabelecida (para detalhes sobre as Regras de Schreinemakers, vide Zen, 1966; Will, 1998; e Candia et al., 2003).

Para ilustrar esses conceitos, pode-se considerar um diagrama de fases de um sistema com apenas um componente, como o dos polimorfos da sílica, $\mathrm{SiO}_{2}$ (Figura 1A).
Uma vez que a Regra das Fases determina que cada ponto invariante $(\mathrm{F}=0)$ pode correlacionar apenas três fases em equilíbrio para $\mathrm{C}=1$, para acomodar as relações entre as sete fases implícitas no sistema, precisa-se de cinco pontos invariantes, configurando um multissistema (Figura 1A). Tome-se agora como exemplo o ponto invariante que correlaciona as fases coesita, quartzo- $\alpha$ e quartzo- $\beta$. Essas três fases só podem coexistir em equilíbrio nas condições definidas pelo ponto invariante, cuja posição no campo $P$ x $T$ é $34 \mathrm{kbar}$ e $1.380^{\circ} \mathrm{C}$ (Mirwald e Massonne, 1980). Em todas as linhas univariantes que emanam desse ponto, o número de graus de liberdade é $1(\mathrm{~F}=1)$ e, sobre cada uma delas, duas fases coexistem $(\mathrm{P}=2)$, sejam coesita e quartzo- $\alpha$, coesita e quartzo- $\beta$, ou quartzo- $\alpha$ e quartzo- $\beta$, separando os campos divariantes $(\mathrm{F}=2)$, nos quais apenas uma dessas fases pode existir em equilíbrio. As linhas univariantes correspondem às reações polimórficas, em que duas fases reagentes estão em equilíbrio, separando dois campos em que cada uma dessas fases terá energia livre menor, sendo, por vez, a fase em equilíbrio. A linha em que quartzo- $\alpha$ e quartzo- $\beta$ são estáveis é chamada de linha da coesita ausente, e sua extensão metaestável é projetada para dentro do campo de estabilidade da coesita, indicada pela linha tracejada na Figura 1B.

Se o sistema for definido por um número maior de componentes, o número de linhas univariantes ao redor do ponto

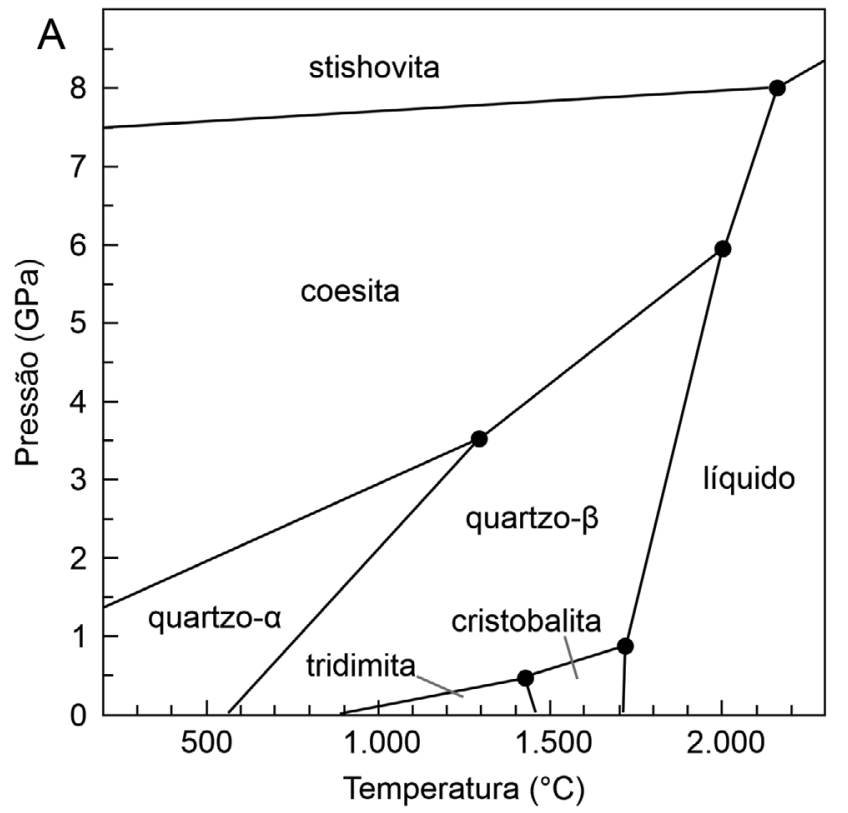

B

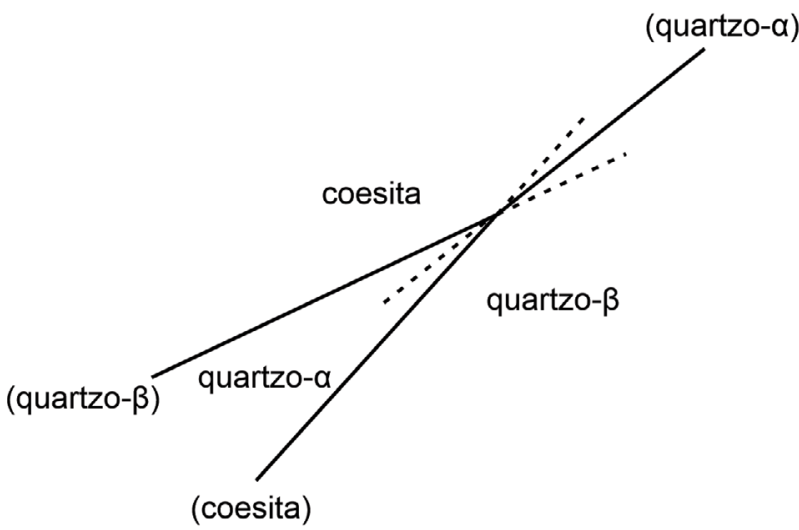

Figura 1. (A) Diagrama de fases com os polimorfos da sílica e líquido, representando as relações da Regra das Fases de Gibbs. Note que a partir de cada ponto invariante emanam três linhas univariantes e que o ângulo entre elas não excede $180^{\circ}$ (extraído de Spear, 1993); (B) representação do ponto invariante envolvendo as fases coesita, quartzo- $\alpha$ e quartzo- $\beta$. Cada linha é nomeada pela sua fase ausente e sua extensão metaestável, representada pela linha tracejada, cai dentro do campo dessa fase. Por exemplo, a linha em que coesita e quartzo- $\alpha$ coexistem é chamada de quartzo- $\beta$ ausente (indicada entre parênteses) e seu prolongamento metaestável se dá dentro do campo do quartzo- $\beta$. 
invariante, bem como o número de fases em equilíbrio no ponto invariante, sobre as linhas univariantes e nos campos divariantes, vão aumentar proporcionalmente, respeitando sempre a Regra de Fases de Gibbs. Se for considerado, por exemplo, o sistema $\mathrm{MgO}-\mathrm{Al}_{2} \mathrm{O}_{3}-\mathrm{SiO}_{2}(\mathrm{C}=3)$, com as fases enstatita, cordierita, quartzo, piropo e sillimanita, as cinco fases poderão coexistir apenas nas condições definidas pelo ponto invariante $(\mathrm{F}=0, \mathrm{P}=5)$, ao redor do qual emanarão cinco linhas univariantes $(F=1, P=4)$, sobre as quais coexistirão sempre quatro fases em equilíbrio, definindo as reações que separam os cinco campos divariantes $(\mathrm{F}=2, \mathrm{P}=3$ ), com paragêneses (associações minerais em equilíbrio) definidas por três das fases anteriores em combinações variadas.

\section{DIAGRAMAS DE COMPATIBILIDADE E GRADES PETROGENÉTICAS}

Diagramas de compatibilidade são aqueles elaborados e usados para mostrar quais associações minerais são estáveis e compatíveis em uma condição $P$ - $T$ específica, em função da variação da composição da rocha. Nesses diagramas, os eixos são as quantidades de componentes do sistema, sendo comum utilizar coordenadas baricêntricas, ou seja, usar como eixos as proporções entre os diferentes componentes.
Esse artifício permite a representação de $n$ componentes em $n-1$ dimensões, por exemplo, a representação de três componentes em duas dimensões, gerando os familiares diagramas triangulares (Figuras 2A). Outros artifícios, como adotar que certos componentes sejam considerados em excesso, permitem a representação de sistemas relativamente complexos em duas dimensões (Thompson, 1957; Candia et al., 2003; Spear, 1993; Bucher e Grapes, 2011). Esses diagramas são úteis para avaliar as relações entre as fases possíveis em uma determinada condição $P$ - $T$, incluindo soluções sólidas entre essas fases.

Grades petrogenéticas são diagramas principalmente com pressão e temperatura como eixos (Figura 2B), nos quais são representadas as condições nas quais ocorrem as reações entre as fases possíveis em determinado sistema químico, possibilitando a representação dos campos de estabilidade de todas as paragêneses possíveis nesse dado sistema. Ainda é possível fazer grades petrogenéticas do tipo $T$ versus $\mathrm{X}$ ou $P$ versus $\mathrm{X}$, ou seja, em que há variação de temperatura, com pressão fixa, e no outro eixo é representada uma variável composicional, por exemplo, $X_{\mathrm{CO} 2}$, que representa a variação $\mathrm{H}_{2} \mathrm{O}-\mathrm{CO}_{2}$ do fluido.

Dispondo de uma grade petrogenética e do diagrama de compatibilidade correspondente (Figura 2), é possível determinar, para qualquer temperatura e pressão, quais são as associações minerais possíveis nesse sistema químico.
A

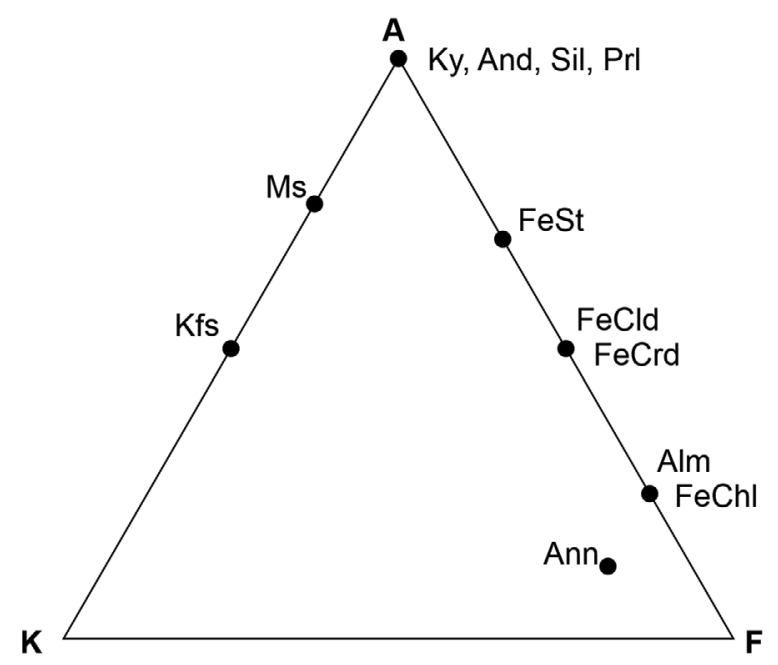

B

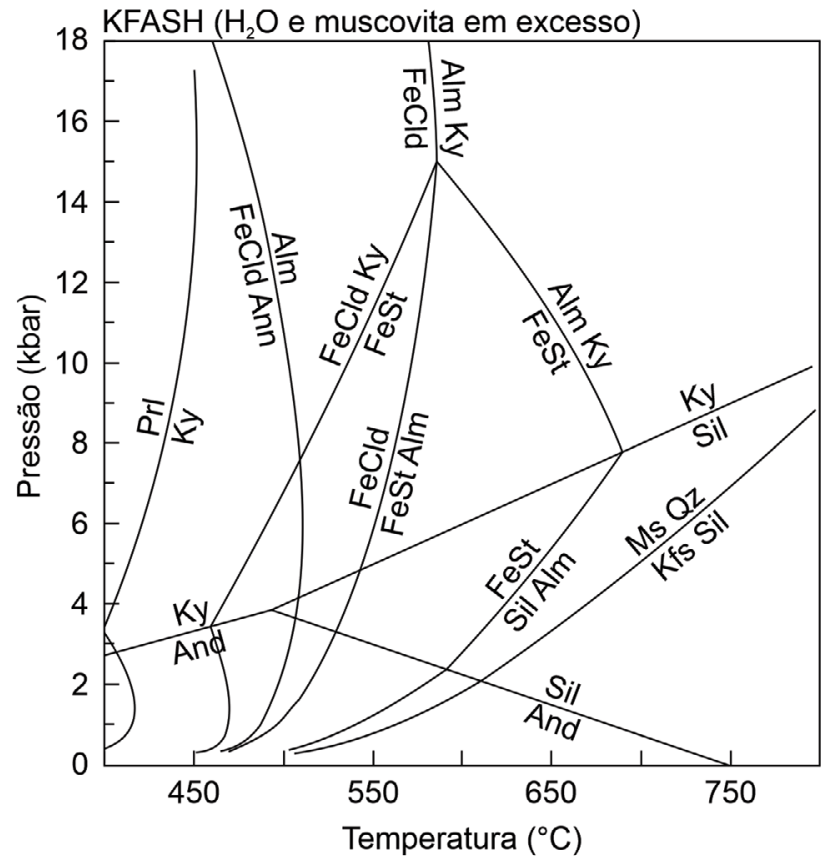

Figura 2. (A) Diagrama de compatibilidade $\mathrm{AKF}\left(\mathrm{Al}_{2} \mathrm{O}_{3}-\mathrm{K}_{2} \mathrm{O}-\mathrm{FeO}\right.$, com $\mathrm{H}_{2} \mathrm{O}$ e $\mathrm{SiO}_{2}$ em excesso) e (B) grade petrogenética no sistema KFASH $\left(\mathrm{Al}_{2} \mathrm{O}_{3}-\mathrm{K}_{2} \mathrm{O}-\mathrm{FeO}-\mathrm{SiO}_{2}-\mathrm{H}_{2} \mathrm{O}\right.$; adaptado de Spear e Cheney, 1989). Note que nesse sistema químico, praticamente sem solução sólida, as linhas representam o limite máximo de estabilidade de um mineral, ou associação mineral. Em um sistema químico mais realista, no qual ocorre solução sólida, esses limites variam de acordo com a composição do sistema. 
Se a composição da rocha for conhecida, pode-se plotar essa composição no diagrama de compatibilidade e saber qual será a sua associação mineral em qualquer temperatura e pressão (Figura 2A). Em um exemplo genérico, se uma rocha for constituída de quartzo, muscovita, Fe-cloritoide e Fe-estaurolita, contendo um fluido rico em $\mathrm{H}_{2} \mathrm{O}$ durante o pico metamórfico, e admitindo um intervalo de pressão entre 5 e $7 \mathrm{kbar}$, o intervalo de temperatura estaria entre 460 e $540^{\circ} \mathrm{C}(5 \mathrm{kbar})$ e 490 e $550^{\circ} \mathrm{C}(7 \mathrm{kbar})$. Isso pode ser inferido, pois a rocha cruzou a reação $\mathrm{FeCtd}+\mathrm{Ky}=\mathrm{FeSt}$, mas ainda não cruzou a reação $\mathrm{FeCtd}=\mathrm{FeSt}+\mathrm{Alm}$, caso contrário, ela teria granada (Alm) em sua mineralogia (Figura 2B).

É fácil perceber, portanto, que essa é, em princípio, uma ferramenta poderosa para a compreensão do metamorfismo em um determinado sistema químico (Spear, 1993) e, por essa razão, a possibilidade de construção de grades petrogenéticas minimamente detalhadas representou grande avanço para a Petrologia Metamórfica (Trommsdorff e Evans, 1972; Spear e Cheney, 1989; Powell e Holland, 1990; Spear, 1993; Spear et al., 2016). Entretanto, a aplicação de grades petrogenéticas tem dois grandes problemas: o primeiro é que quanto mais componentes são considerados, mais complexas e difíceis de ler as grades petrogenéticas se tornam. Por exemplo, o sistema KFMASH $\left(\mathrm{K}_{2} \mathrm{O}-\mathrm{FeO}-\mathrm{MgO}-\mathrm{Al}_{2} \mathrm{O}_{3}-\right.$ $\mathrm{SiO}_{2}-\mathrm{H}_{2} \mathrm{O}$ ) é o menor sistema químico necessário para descrever quimicamente as fases minerais presentes em rochas pelíticas, e grades petrogenéticas construídas nesse sistema já não são graficamente tão simples. Para uma análise realmente quantitativa de rochas metapelíticas são necessários mais componentes, tais como $\mathrm{Na}_{2} \mathrm{O}, \mathrm{CaO}, \mathrm{MnO}, \mathrm{TiO}_{2} \mathrm{e}$ $\mathrm{Fe}_{2} \mathrm{O}_{3}$, de modo que, por exemplo, o campo de estabilidade de minerais como plagioclásio, óxidos de $\mathrm{Fe}$ e Ti possam ser considerados, ou o efeito do $\mathrm{MnO}$ na granada possa ser avaliado. Não faz parte do escopo do presente trabalho discutir essas variações de campo de estabilidade dos minerais dada as variações composicionais. Para isso, recomenda-se a leitura dos textos de White et al. (2000, 2014b), que investigam as influências de $\mathrm{TiO}_{2}$ e $\mathrm{Fe}_{2} \mathrm{O}_{3}$ e, depois, do $\mathrm{MnO}$, respectivamente, nos campos de estabilidade dos minerais das rochas pelíticas.

O maior empecilho para que as grades petrogenéticas descrevam sistemas reais é o fato de que a maior parte dos minerais formadores de rocha apresenta solução sólida, cuja extensão varia de acordo com $P$ e $T$. Isso gera algumas diferenças de comportamento entre sistemas reais e sistemas idealizados que não tenham soluções sólidas:

- Em sistemas reais, ao contrário do que acontece em sistemas idealizados, é frequente encontrar associações com variância maior do que 2 . Por exemplo, no diagrama AFM da Figura 3, apenas a composição representada pelo ponto amarelo apresentaria uma associação de variância 2 ;

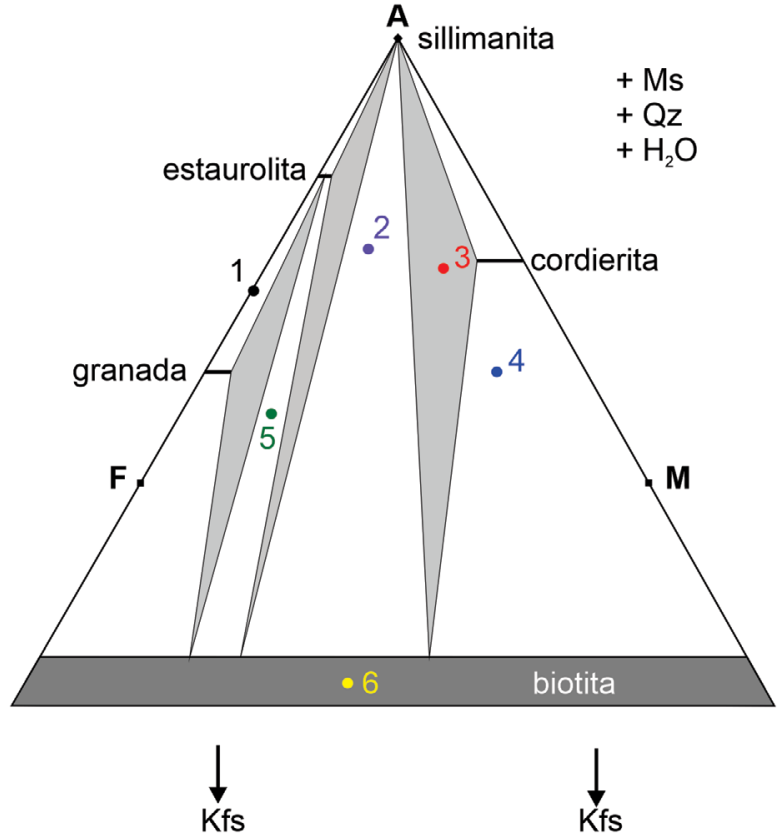

Fonte: modificado de Spear (1993) e Bucher e Grapes (2011).

Figura 3. Diagrama AFM genérico. Note que a maior parte das composições indicadas pelos pontos resulta em associações de dois minerais (+ fases em excesso), exceto a composição representada pelo ponto 3 , em vermelho (cordierita + sillimanita + biotita + fases em excesso), e a composição representada pelo ponto 6 , em amarelo, que resulta em apenas biotita (+ fases em excesso).

- Um corolário de $i$ é que, enquanto a evolução de sistemas ideais pode ser descrita por meio de séries de reações realmente univariantes, em sistemas reais, reações univariantes são raras, e as condições $P-T$ para a entrada ou saída de uma determinada paragênese serão diferentes para sistemas com composições diferentes (Figura 4);

- A variação da composição dos minerais de acordo com $P$ e $T$ faz com que, em sistemas reais, as proporções entre os minerais variem continuamente. Um efeito combinado disso com a própria variação composicional dos minerais é que os coeficientes estequiométricos de uma determinada reação também mudam de acordo com $P$ e $T$. A Figura 5 representa a entrada da estaurolita e o consumo de granada e clorita, pela reação genérica (Equação 2):

muscovita + granada + clorita $\leftrightarrow$

quartzo + estaurolita + biotita $+\mathrm{H}_{2} \mathrm{O}$

As mudanças nas composições e proporções modais de granada e clorita de acordo com as condições $P$ - $T$ fazem com que, seguindo a trajetória marcada em vermelho (Figura 5), a clorita seja totalmente consumida pela reação, deixando a rocha 

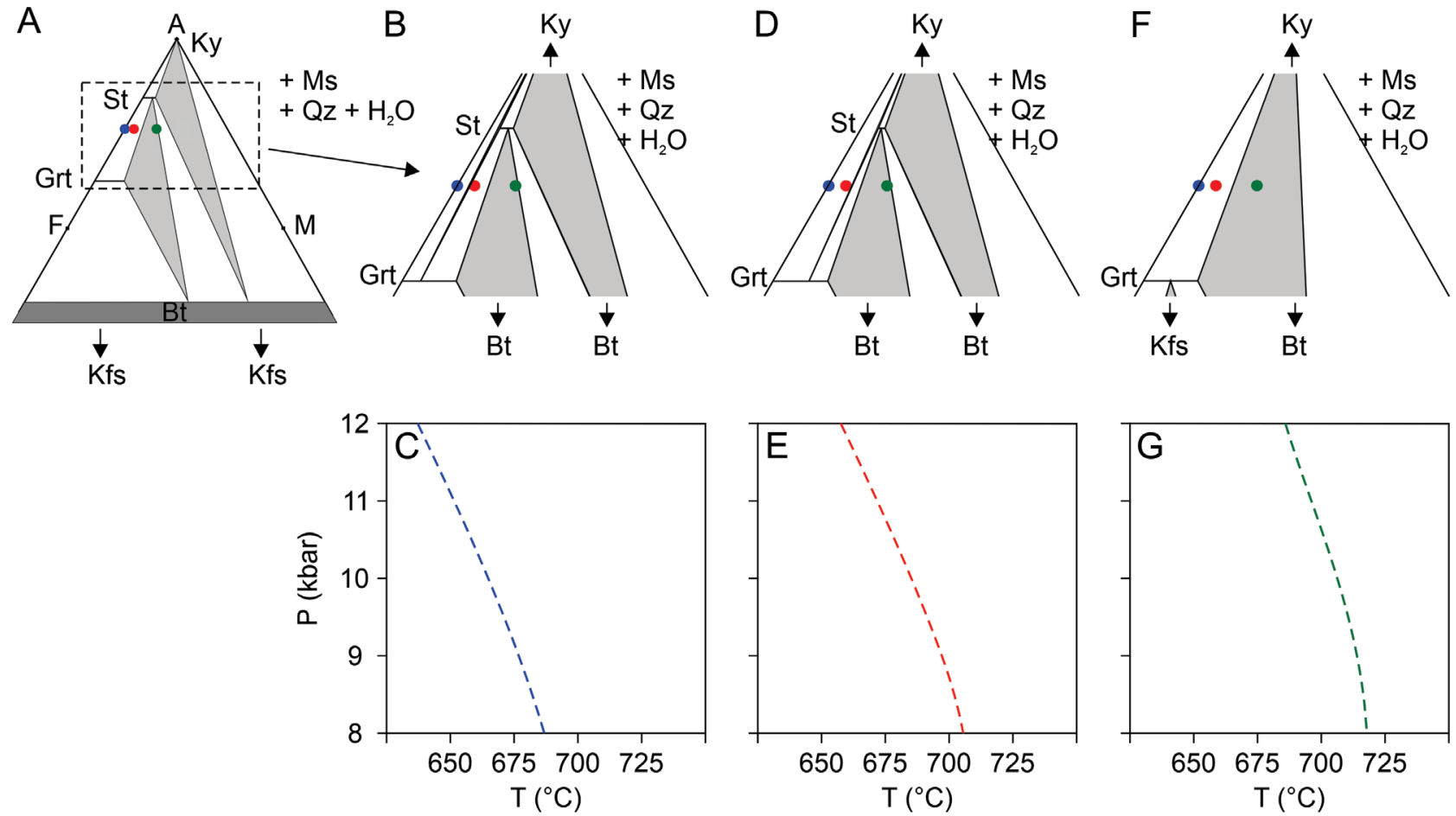

Fonte: adaptado e modificado de Spear (1993) e Bucher e Grapes (2011).

Figura 4. (A, B, D, F) Diagramas AFM para diferentes condições $P-T$ e $(\mathrm{C}, \mathrm{E}, \mathrm{G})$ diagramas $P-T$ esquemáticos mostrando como a quebra da estaurolita se dá em diferentes temperaturas para diferentes composições de rocha, sendo menor para a composição representada pelo ponto azul $(B, C)$, intermediária para a composição do ponto vermelho (D, E) e maior para a composição do ponto verde $(\mathrm{F}, \mathrm{G})$.

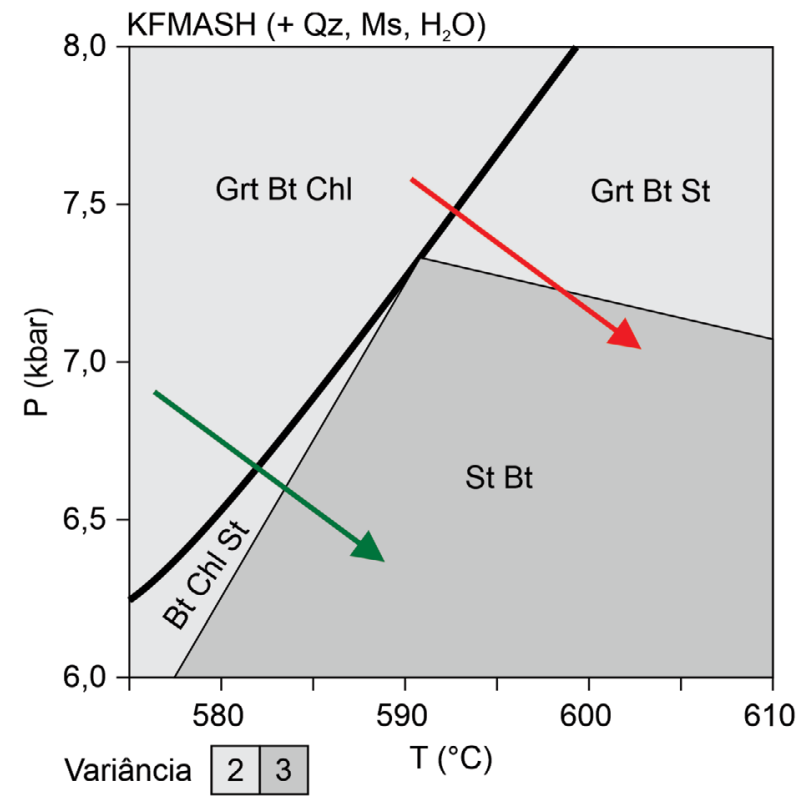

Fonte: modificada de Powell et al. (1998).

Figura 5. Exemplo de pseudosseção no sistema KFMASH ilustrando a variação nas reações minerais de acordo com as condições $P-T$. com a paragênese granada + biotita + estaurolita + muscovita + quartzo. Enquanto isso, seguindo a trajetória marcada em verde, a granada é consumida totalmente, produzindo a paragênese clorita + biotita + estaurolita + muscovita + quartzo;

- Em sistemas ideais, a adição de um componente extra implica a adição de uma fase a mais que o comporte. Em sistemas reais esse não necessariamente é o caso. Por exemplo, se quantidades suficientemente pequenas de $\mathrm{Na}_{2} \mathrm{O}, \mathrm{CaO}$, $\mathrm{MnO}$ e $\mathrm{Fe}_{2} \mathrm{O}_{3}$ forem adicionadas a um sistema $\mathrm{KFMASH}$, o $\mathrm{Na}_{2} \mathrm{O}$ será incorporado na muscovita, o $\mathrm{CaO}$ e o $\mathrm{MnO}$ podem ser incorporados à granada e $\mathrm{o} \mathrm{Fe}_{2} \mathrm{O}_{3}$ pode ser distribuído entre os diversos minerais. Mesmo que não acarrete na adição de novas fases, esses componentes afetam os campos de estabilidade de todas as fases. No entanto, se o limite de saturação desses componentes for atingido nesses minerais, todas as novas fases devem ser consideradas, como plagioclásio, rutilo e os óxidos de Fe e Ti.

\section{VOLUMES DE EQUILÍBRIO}

O conceito de volume de equilíbrio é um dos mais importantes em Petrologia Metamórfica, mesmo que por vezes 
não seja discutido explicitamente. O volume de equilíbrio é o volume de rocha que está efetivamente em equilíbrio químico durante o metamorfismo. Por exemplo, seja uma rocha com bandas metapelíticas e calcissilicáticas, as quais apresentam paragêneses típicas desses dois tipos de rocha. Os minerais de cada banda estarão em equilíbrio entre si, mas os minerais da banda metapelítica não estarão em equilíbrio com os minerais da banda calcissilicática e vice-versa, pois, se esse fosse o caso, a rocha seria uniforme, e apresentaria uma única paragênese. Nesse caso, pode-se dizer que as bandas são maiores do que o volume de equilíbrio, ou seja, os elementos em uma banda não conseguem se difundir por uma distância grande o suficiente para chegar à outra. Outro exemplo do mesmo fenômeno são os porfiroblastos, grandes o suficiente para que seus núcleos não tenham comunicação com o restante da rocha, de modo que sua composição apresente intensa zonação química, demonstrando que não houve reequilíbrio constante durante o crescimento do mineral. Nesse caso, os núcleos dos minerais são efetivamente retirados do volume de equilíbrio da rocha, pois eles não estão em equilíbrio com a matriz.

A dimensão do volume de equilíbrio varia de acordo com as condições $P-T$, a presença de fluidos e as características texturais; além disso, ela é diferente para cada elemento químico, uma vez que a difusividade é característica de cada um (Stüwe, 1997; Carlson, 2002; White et al., 2008). Esses fatores fazem com que seja efetivamente impossível determinar qual era a dimensão e o formato do volume de equilíbrio em um determinado momento da história de uma rocha. Vários estudos mostram como problemas relacionados ao volume de equilíbrio podem ocorrer mesmo em situações em que isso não é tão óbvio quanto nos exemplos anteriores. Esse é um problema atual na Petrologia Metamórfica, e existe extensa literatura a respeito, tanto de caráter teórico quanto discutindo diversas abordagens para contornar esse problema (e.g. Joesten, 1977; Stüwe, 1997; Carlson, 2002; White et al., 2002, 2008; Štipska et al., 2010; Carlson et al., 2015; Palin et al., 2016; Lanari e Engi, 2017; Lanari e Duesterhoeft, 2019; Duesterhoeft e Lanari, 2020).

\section{PSEUDOSSEÇÕES}

\section{Conceitos e requerimentos}

O primeiro passo para qualquer modelagem petrológica é uma boa descrição petrográfica, que é o ponto inicial em que se decide o que se pretende responder com a pseudosseção e o que será modelado.

A pseudosseção é um mapa de associações minerais no espaço $P$ - $T$ que mostra somente as associações minerais permitidas pela composição química da rocha, além das reações, ou segmentos de reações que essa composição consegue "ver", minimizando assim os problemas mostrados anteriormente. Ao utilizar a composição de uma amostra ou de um volume de equilíbrio para calcular as reações e associações minerais compatíveis com a composição em qualquer sistema químico desejado (Stüwe, 1997), incluindo os mais complexos, é possível obter modelos que representam da melhor maneira possível as variações composicionais das rochas que ocorrem na natureza (Powell et al., 1998; White et al., 2014b). Os campos de uma pseudosseção podem ser contornados para variáveis composicionais e de moda das fases, facilitando a inferência de condições e de trajetórias $P$ - $T$, baseadas em variações texturais e composicionais das fases (Will, 1998; Powell et al., 2005). A confecção de pseudosseções, assim como a termobarometria convencional, depende de três fatores: as descrições termodinâmicas das fases, os modelos de atividade-composição (conhecidos como $a$-X models) e softwares capazes de realizar os cálculos (Powell e Holland, 1988, 2008; Powell et al., 1998; White et al., 2014a; Green et al., 2016; Lanari e Duesterhoeft, 2019).

A primeira pseudosseção que apareceu na literatura petrológica foi calculada por Hensen (1971) com o nome de "diagrama de fases P-T para uma composição específica". Muito tempo depois, Roger Powell cunhou o termo "pseudosseção" para esse tipo de diagrama, relacionando-o ao conceito de "diagrama de fase total" (Powell et al., 1998, 2005). A adoção do termo por parte do grupo de pesquisa que desenvolve o programa THERMOCALC fez com ele se tornasse muito difundido, mas vários pesquisadores preferem o termo mais descritivo, "diagrama de fase isoquímico" (e.g. Lanari e Duesterhoeft, 2019).

As descrições termodinâmicas das fases são o conjunto de propriedades termodinâmicas de cada fase, tais como entalpia e entropia de formação, volume molar etc. Esses dados são organizados em bancos de dados termodinâmicos internamente consistentes, que são uma forma coerente de apresentar os dados de diversos experimentos. Dois grupos principais de bases de dados são geralmente utilizados em Petrologia Metamórfica: a base de dados de Berman (1988) e bases mais recentes derivadas, e.g. JUN92 (de Capitani e Petrakakis, 2010) e BED 92 (Duesterhoeft, 2017), e o banco de dados de Holland e Powell $(1985,1998,2011)$.

Os modelos de atividade-composição descrevem o comportamento termodinâmico dos minerais que apresentam solução sólida. Existem diversos modelos para cada mineral. Os modelos de atividade descrevem como se dá a distribuição dos elementos químicos entre os sítios cristaloquímicos dos minerais, e levam em conta as energias envolvidas quando apenas um ou mais de um sítio cristalino é envolvido nas substituições químicas. De modo simplista, os modelos são divididos em ideal e não ideal (Spear, 1993). Os modelos de atividade realistas não são simples de serem construídos 
e não podem ser testados diretamente, apenas por meio dos resultados de cálculos termobarométricos que os utilizam. Justamente por isso, os modelos de atividade são o elo mais frágil entre os três fatores citados anteriormente (Powell e Holland, 1993; Spear, 1993; Diener e Powell, 2012; Green et al., 2016; Lanari e Duesterhoeft, 2019).

Existem atualmente três softwares utilizados para a construção de pseudosseções: Perple_X (Connolly e Kerrick, 1987), Theriak-Domino (Capitani e Brown, 1987) e THERMOCALC (Powell e Holland, 1988). O Perple_X e o Theriak-Domino utilizam o método da minimização da energia livre de Gibbs, que permite o reconhecimento das paragêneses em equilíbrio, ou seja, onde $\Delta \mathrm{G}=0$, localizando assim todos os campos de estabilidade entre as fases (Connolly e Kerrick, 1987; Connolly, 1990). Isso permite que os diagramas sejam calculados de maneira automatizada, independentemente da experiência do usuário. Os três programas produzem os mesmos resultados, desde que sejam escolhidas exatamente as mesmas condições iniciais, a mesma composição de rocha, o mesmo sistema químico, os mesmos modelos de atividade e banco de dados termodinâmicos. O Perple_X e o Theriak-Domino podem "perder" alguns campos pequenos se o passo de interação de cálculo for muito grande. Nesse caso, execuções adicionais, ou com passo mais curto (maior número de interações), devem ser utilizadas, ou ainda escolhendo janelas P-T menores em áreas críticas. Ambos os softwares são distribuídos com os bancos de dados citados anteriormente, e com modelos de atividade compatíveis com esses bancos. Isso garante maior flexibilidade, mas também permite a combinação de modelos de atividade-composição incompatíveis entre si, o que pode causar problemas. Desse modo, é imprescindível que o usuário saiba quais modelos de atividade está escolhendo e deve sempre combinar modelos do mesmo sistema químico. Por exemplo, um cálculo feito usando modelos de micas que não considere $\mathrm{Fe}^{3+}$, não deve ser combinado com modelos de atividade de granada e estaurolita que leve em conta $\mathrm{Fe}^{3+}$.

Ao contrário dos programas citados anteriormente, o THERMOCALC calcula relações de equilíbrio por meio da resolução de equações não lineares. Dessa forma, os diagramas são calculados linha por linha e ponto por ponto, a partir de um conjunto de fases informadas pelo usuário. Isso permite maior controle sobre os cálculos, com erros sendo detectados facilmente e campos restritos sendo calculados de forma eficiente. Por outro lado, como as fases são escolhidas pelo usuário, abre-se a possibilidade de que curvas e pontos metaestáveis sejam calculados. Além disso, os cálculos com o THERMOCALC demandam muito mais tempo e perícia do usuário, uma vez que usuários experientes têm conhecimento das fases esperadas em um determinado sistema e das relações básicas entre elas, além de serem capazes de utilizar o programa de forma mais veloz.
O THERMOCALC foi desenhado para operar com o banco de dados de Holland e Powell $(1998,2011)$ e os modelos de atividade construídos pelo grupo de pesquisa responsável pelo software. É possível modificar os modelos de atividade manualmente e fazer com que o programa opere com outro banco de dados, mas isso requer conhecimentos avançados do software. Diferentes versões do programa são compatíveis com diferentes versões do banco de dados e dos modelos de atividade, e, no momento, apenas versões mais recentes do pacote são distribuídas "oficialmente". Dessa forma, o THERMOCALC é menos flexível nesse aspecto, mas restringe a possibilidade de erros serem causados por incompatibilidades entre os diferentes modelos de atividade.

\section{Aspectos topológicos}

Em uma pseudosseção, todas as linhas marcam limites em que a moda de um mineral é zero, na qual o mineral aparece, ou é gerado, ou que desaparece, pelo seu consumo. Os pontos são locais em que a moda de duas fases é igual a zero, e há sempre quatro linhas que se originam de cada ponto, que separam quatro campos, dos quais dois têm a mesma variância, tal como previsto pelas Regras de Schreinemakers. Se essa variância é $F$, as variâncias dos outros dois campos serão $F+1$ e $F-1$, e sua disposição será tal que, cruzando uma linha, a mudança na variância é sempre 1 (Figura 6), e cruzando um ponto, a mudança de variância é sempre 2 ou 0 (Powell et al., 1998; Will, 1998). Na região ao redor de um ponto, a moda de determinada fase muda ao longo das linhas de acordo com as variações de $P$ e $T$, diminuindo até chegar a zero no ponto, ou aumentando a partir do ponto.

Na Figura 6 são representadas as linhas em que as modas das fases "b" e "c" são iguais a zero. Na Figura 6A está indicada a linha com o sentido da diminuição da fase "b" decorrente do seu consumo para formar a fase " $c$ " $(a+b=$ c), e a Figura 6B mostra o sentido da diminuição na moda da fase "b" em direção às linhas a(b) e ac(b), em que b $=0$. Essas duas situações representam as situações de geração e consumo de uma fase na pseudosseção. Linhas verdadeiramente univariantes em pseudosseções não são comuns e, normalmente, só ocorrem em sistemas químicos mais simples, tais como o sistema KFMASH. Mesmo nesse caso, os programas conseguem, partindo da composição da rocha, "ver" a existência de linhas univariantes e calcular apenas segmentos delas.

Moda zero pode representar o fim ou o primeiro aparecimento de determinada fase; isso pode ser visto nas linhas verdadeiramente univariantes da pseudosseção, que podem ser entendidas como campos estreitos. Na Figura $6 \mathrm{C}$, a linha vermelha representa a linha univariante para a reação $\mathrm{Grt}+\mathrm{Chl}=\mathrm{Bt}+\mathrm{St}$, que, na Figura $6 \mathrm{D}$, é mostrada 
como um campo estreito, em que, à esquerda, a moda da estaurolita é zero $(\mathrm{St}=0)$, representando o primeiro aparecimento de estaurolita, e, à direita, a moda da clorita é zero $(\mathrm{Chl}=0)$, representando o desaparecimento/consumo de clorita. Assim, a construção das pseudosseções é feita por meio do cálculo de linhas e pontos em que a moda é zero. Por exemplo, no THERMOCALC, entra-se com a associação Grt, Chl, Bt, St (+ Qz, Ms e $\mathrm{H}_{2} \mathrm{O}$, que são as fases em excesso); em seguida, é calculada a linha $\mathrm{St}=0$, depois $\mathrm{Chl}=0, \mathrm{Grt}=0$ e o ponto [Grt, $\mathrm{Chl}]=0$ para se obter as coordenadas $P-T$ das linhas e pontos, seguindo o exemplo da Figura 6D.

Ter essas relações em mente é especialmente útil para a construção de pseudosseções usando o THERMOCALC, mas também serve para conferir os resultados obtidos com os outros softwares. As cores dos campos das pseudosseções indicam sua variância, em geral com os campos mais escuros representando maior variância e, consequentemente, menor número de fases, enquanto os campos mais claros representam menor variância e têm o maior número de fases. As linhas verdadeiramente univariantes, quando ocorrem, podem ser destacadas em espessura diferente.
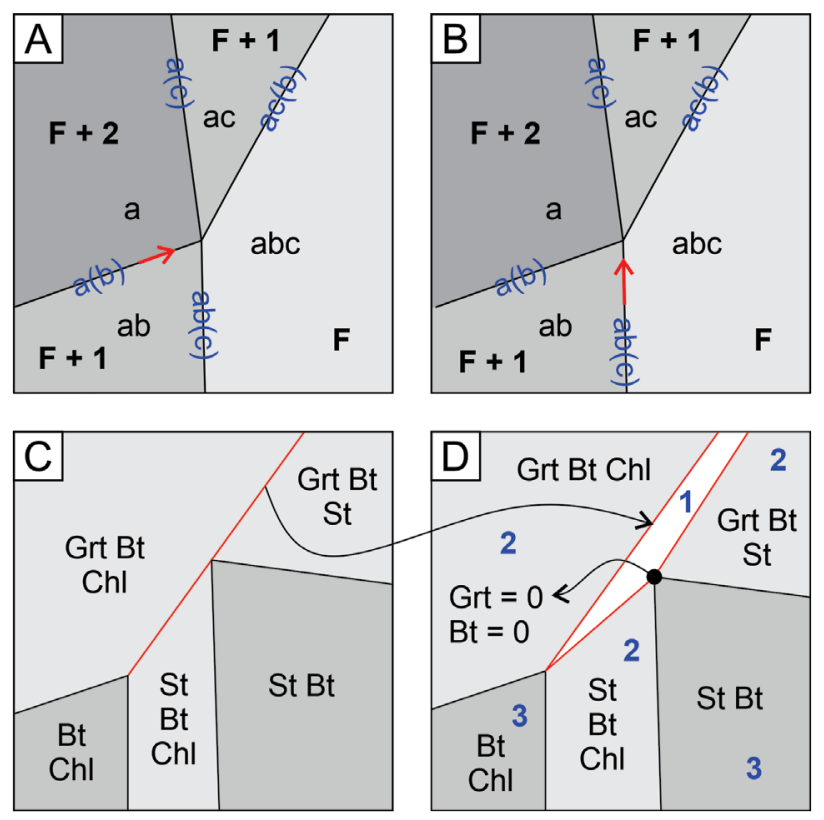

Fonte: modificado de Powell et al. (2006).

Figura 6. Modelo esquemático mostrando a relação entre pontos invariantes e campos em uma pseudosseção. Em (A), seguindo a seta vermelha, ocorre o ganho da fase "c"; em (B), o caminho da seta vermelha indica a perda da fase "b"; (C) ilustra uma linha univariante para a reação $\mathrm{Grt}+\mathrm{Chl}=\mathrm{Bt}+\mathrm{St}$; e em (D), observa-se que a linha é representada por um campo estreito. Os números em azul indicam a variância dos campos.

\section{Aplicações em rochas metapelíticas}

Rochas metapelíticas são derivadas do metamorfismo de rochas sedimentares ricas em argila e têm papel crucial no estudo de terrenos metamórficos, dada a facilidade com que desenvolvem associações minerais com as mudanças no campo $P$ - $T$. Historicamente, o estudo do metamorfismo das rochas pelíticas marca um dos primeiros exemplos de metamorfismo progressivo bem investigados e documentados, nas Highlands da Escócia por George Barrow (1893, 1912).

O sistema químico mais utilizado para o estudo do metamorfismo de rochas pelíticas é o KFMASH, que compreende mais de $90 \%$ da composição de xistos pelíticos (Spear e Cheney, 1989). A grade de Spear e Cheney (1989), calculada com base no banco de dados termodinâmicos de Berman (1988), e usando muscovita, quartzo e $\mathrm{H}_{2} \mathrm{O}$ em excesso, leva em conta algumas premissas petrológicas e fixa a posição de alguns pontos invariantes e de reações univariantes para dar início aos cálculos. Uma versão levemente modificada foi publicada no site de Frank Spear e é aqui reproduzida na Figura 7.

Powell e Holland (1990) calcularam uma grade petrogenética no sistema KFMASH para rochas metapelíticas sob condições de fácies xisto verde a anfibolito (Figura 8), usando o banco de dados de Holland e Powell (1985), com

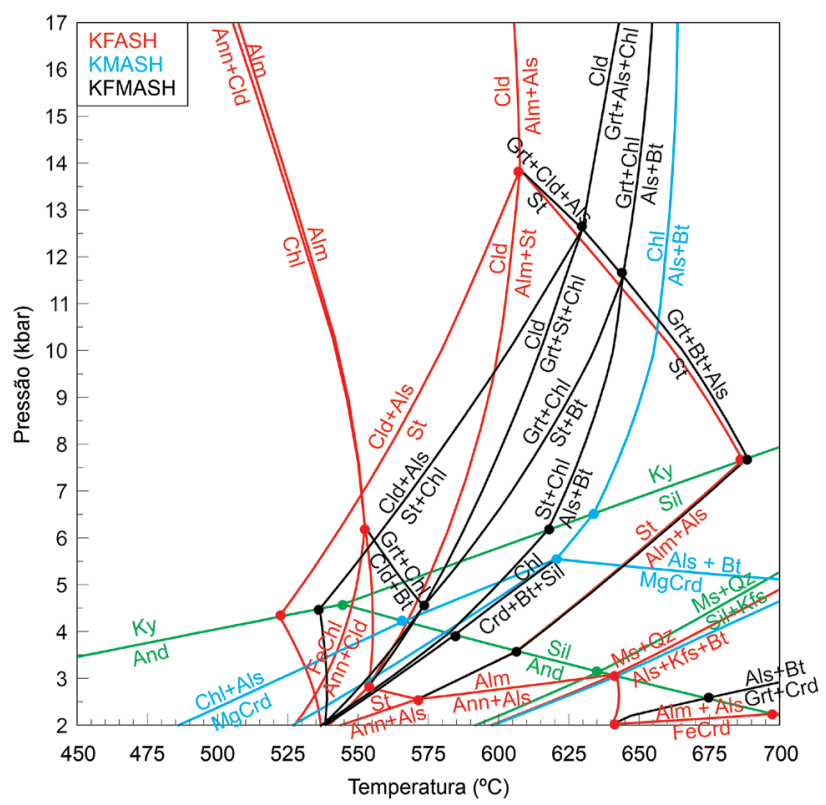

Figura 7. Grade petrogenética para o sistema KFMASH baseada nas grades KFASH e KMASH. Pontos representam pontos invariantes em cada sistema. Extraído do site de Frank Spear, sendo versão levemente modificada de Spear e Cheney (1989), com a mudança de um ponto invariante envolvendo a reação $\mathrm{Cld}+\mathrm{Bt}=\mathrm{Grt}+\mathrm{Chl}$, para posição de baixa $P$. 


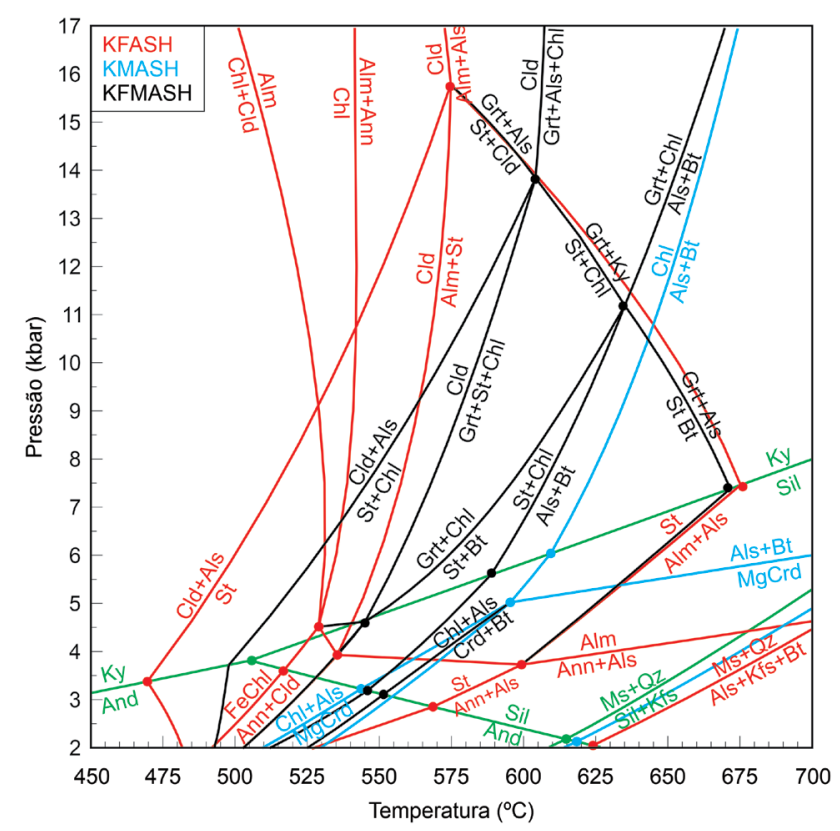

Figura 8. Grade petrogenética construída para o Sistema KFMASH (+Ms $\left.+\mathrm{Qz}+\mathrm{H}_{2} \mathrm{O}\right)$. Redesenhado a partir de Powell et al. (1998), na mesma escala da Figura 7.

equilíbrios entre clorita, cloritoide, biotita, granada, estaurolita, cianita, sillimanita, andaluzita e cordierita, considerando, tal como no caso da grade de Spear e Cheney (1989), muscovita, quartzo e $\mathrm{H}_{2} \mathrm{O}$ em excesso. Ao comparar as grades petrogenéticas das Figuras 7 e 8, observa-se que as topologias são praticamente as mesmas e que ambas foram determinadas com base em dados experimentais de reações dos subsistemas KFASH e KMASH, mas as diferenças estão no método de obtenção. Na grade da Figura 7, dos quatro pontos invariantes, apenas dois foram determinados experimentalmente (Spear e Cheney, 1989); os demais foram fixados com base em observações de paragêneses naturais. Já para a grade da Figura 8, todos os pontos invariantes e curvas univariantes foram calculados com base nos dados do banco de dados internamente consistentes até então disponível (Powell e Holland, 1990). Apesar da qualidade dos dados experimentais de equilíbrios minerais disponíveis na época, Powell e Holland (1990) conseguiram calcular todas as curvas para equilíbrios em baixa pressão com as fases citadas anteriormente. Ainda existem diferenças quanto as substituições admitidas nos minerais, pois na primeira apenas ocorre troca entre $\mathrm{Fe}$ e $\mathrm{Mg}$, e na segunda a substituição tschermak é adicionada quando pertinente, o que aumenta a curvatura das reações envolvendo filossilicatos.

Para demonstrar a aplicação do uso de pseudosseções, foi escolhido um metapelito aluminoso do Grupo Carrancas (Trouw et al., 1983). A amostra SC-07 consiste em um cloritoide-estaurolita-granada-clorita filito (Pavan, 2010), cuja composição foi utilizada para a construção de pseudosseções em diferentes sistemas químicos, mas usando as mesmas relações de atividade-composição para membros finais a partir do banco de dados internamente consistentes de Holland e Powell (2011). A pseudosseção calculada no sistema KFMASH (Figura 9) mostra boa concordância com as grades petrogenéticas, sobretudo para as curvas calculadas no sistema KFASH (Figura 8). Boa parte do diagrama é diferente e isso se deve à composição da rocha conside-

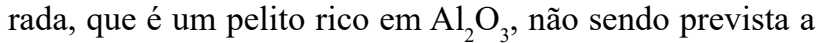
ocorrência de feldspato potássico e cordierita, dentro da janela $P-T$ investigada.

Partindo da mesma composição usada para calcular a pseudosseção da Figura 8 e adicionando os componentes $\mathrm{Na}_{2} \mathrm{O}$ e $\mathrm{CaO}$ é possível ver que isso permite que fases como epidoto, plagioclásio, margarita e a solução sólida muscovita-paragonita sejam consideradas nos cálculos, especialmente em equilíbrios estabelecidos sob condições de fácies xisto verde e anfibolito (White et al., 2014a), e o $\mathrm{CaO}$ pode também particionar na granada, alterando sua estabilidade. Já o $\mathrm{TiO}_{2}$ e o $\mathrm{Fe}_{2} \mathrm{O}_{3}$, apesar de ocorrerem em baixas concentrações em rochas metapelíticas, são componentes que podem influenciar no equilíbrio das fases principais, além de possibilitar a inclusão de membros das séries ilmenita-hematita e ulvoespinélio-magnetita, comumente como fases acessórias nos equilíbrios. White et al. $(2000,2007)$ e Diener e Powell (2010) estudaram os efeitos do $\mathrm{TiO}_{2}$ e $\mathrm{Fe}_{2} \mathrm{O}_{3}$ em associações minerais de metapelitos, adicionando modelos termodinâmicos para soluções sólidas entre ilmenita-hematita e magnetita-ulvoespinélio, e modificando os modelos de atividade-composição dos silicatos, de modo que permitisse calcular a distribuição desses componentes não só nos óxidos, mas também nos silicatos, demonstrando que quantidades baixas a moderadas de $\mathrm{TiO}_{2}$ e $\mathrm{Fe}_{2} \mathrm{O}_{3}$ realmente têm pouco efeito nos equilíbrios entre silicatos formados sob condições de fácies xisto verde a anfibolito. Grandes quantidades de $\mathrm{TiO}_{2}$ têm também pouco efeito na estabilidade dos silicatos, mas, por outro lado, rochas ricas em $\mathrm{Fe}_{2} \mathrm{O}_{3}$ apresentam sucessão mineral distinta das sequências barrovianas clássicas, com acentuada redução no campo de estabilidade de estaurolita e granada para pressões elevadas (White et al., 2000, 2007). O efeito combinado da inclusão de $\mathrm{Fe}_{2} \mathrm{O}_{3}$ e $\mathrm{TiO}_{2}$ nos cálculos das pseudosseções pode ser significativo na estabilidade de associações minerais envolvendo silicatos nas rochas metapelíticas, possibilitando ainda a inclusão de novas fases minerais, antes não consideradas (White et al., 2000, 2007). Por exemplo, ao incluir esses componentes, a reação $\mathrm{Grt}+\mathrm{Chl}=\mathrm{Bt}+\mathrm{St}$ passa a considerar ilmenita nos reagentes para a formação de magnetita ou rutilo, dependendo do estado de oxidação do equilíbrio e das condições de pressão em que a reação ocorre (Diener e Powell, 2010). 


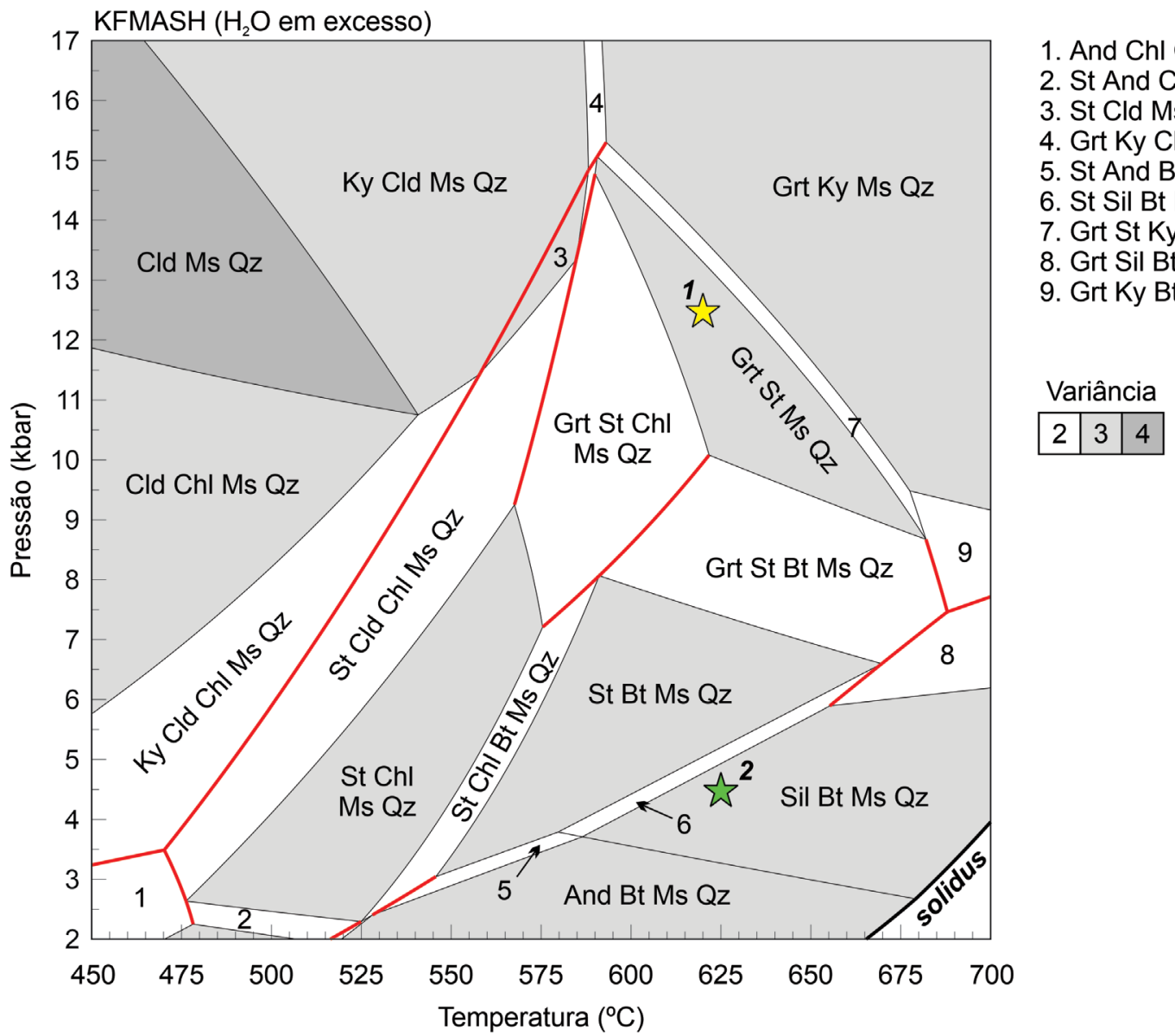

Figura 9. Pseudosseção $P-T$ calculada no sistema KFMASH para a amostra SC-07. As linhas vermelhas representam as linhas univariantes. $\mathrm{SiO}_{2}(70,14), \mathrm{Al}_{2} \mathrm{O}_{3}(16,18), \mathrm{FeO}(5,5), \mathrm{MgO}(2,46)$ e $\mathrm{K}_{2} \mathrm{O}(3,13)$, em \% molar. As associações minerais indicadas pelas estrelas amarela (1) e verde (2) são exemplos para serem comparados com a variação do sistema químico modelo (ver Tabela 1).

$\mathrm{O}$ caso do $\mathrm{Fe}_{2} \mathrm{O}_{3}$ tem a especificidade de envolver $\mathrm{Fe}$ em diferentes estados de oxidação. Métodos de análise mais comuns e habituais, tais como fluorescência de raio $\mathrm{X}$ e microssonda eletrônica, não distinguem entre $\mathrm{Fe}^{2+} \mathrm{e}$ $\mathrm{Fe}^{3+}$. Além disso, a quantidade de $\mathrm{Fe}^{3+}$ pode ser mudada por pequenas alterações intempéricas, pela existência de vacâncias, pelo uso de balanço total de cargas (Proyer et al., 2004) e na própria preparação da amostra, o que faz desse um problema de difícil abordagem no modelamento termodinâmico — vide Diener e Powell (2010) para uma discussão específica sobre o assunto.

Agora, da mesma maneira, após a adição de $\mathrm{Na}_{2} \mathrm{O}$ e $\mathrm{CaO}$ e examinar seus efeitos, o que ocorre em um sistema químico quase completo? No sistema NCKFMASHTO, seria possível considerar, para o cálculo dos equilíbrios, fases adicionais como albita, plagioclásio, paragonita, margarita, epidoto, ilmenita, rutilo, magnetita e hematita. Entretanto, o aparecimento dessas fases na modelagem é função da composição química da rocha e da janela $P-T$ adotada. Para a composição selecionada, apenas a ilmenita aparece como fase adicional (Figura 10), sendo o mineral que incorpora a maior parte do $\mathrm{TiO}_{2}$ e $\mathrm{Fe}_{2} \mathrm{O}_{3}$, e, portanto, estável em todo o intervalo $P$ - $T$ considerado, aumentando a variância dos campos, porém sem que sua inclusão seja responsável por alterar a topologia entre as pseudosseções nos sistemas KFMASH e NCKFMASHTO. A inclusão de $\mathrm{Na}_{2} \mathrm{O}$ e CaO, em função da ausência de fases adicionais possíveis nos equilíbrios, não muda drasticamente a topologia da maioria dos campos da pseudosseção. Entretanto, a adição desses componentes diminui drasticamente a temperatura da curva solidus e leva ao aumento geral da variância na janela $P-T$ considerada, eliminando todas as curvas univariantes. A título de comparação, a Tabela 1 mostra, para duas condições $P-T$ fixas, como mudam as associações minerais calculadas, em função da mudança de sistema químico.

Embora a amostra SC-07 possua alto teor de $\mathrm{Al}_{2} \mathrm{O}_{3}$, diferentemente do que se tem na pseudosseção no sistema 


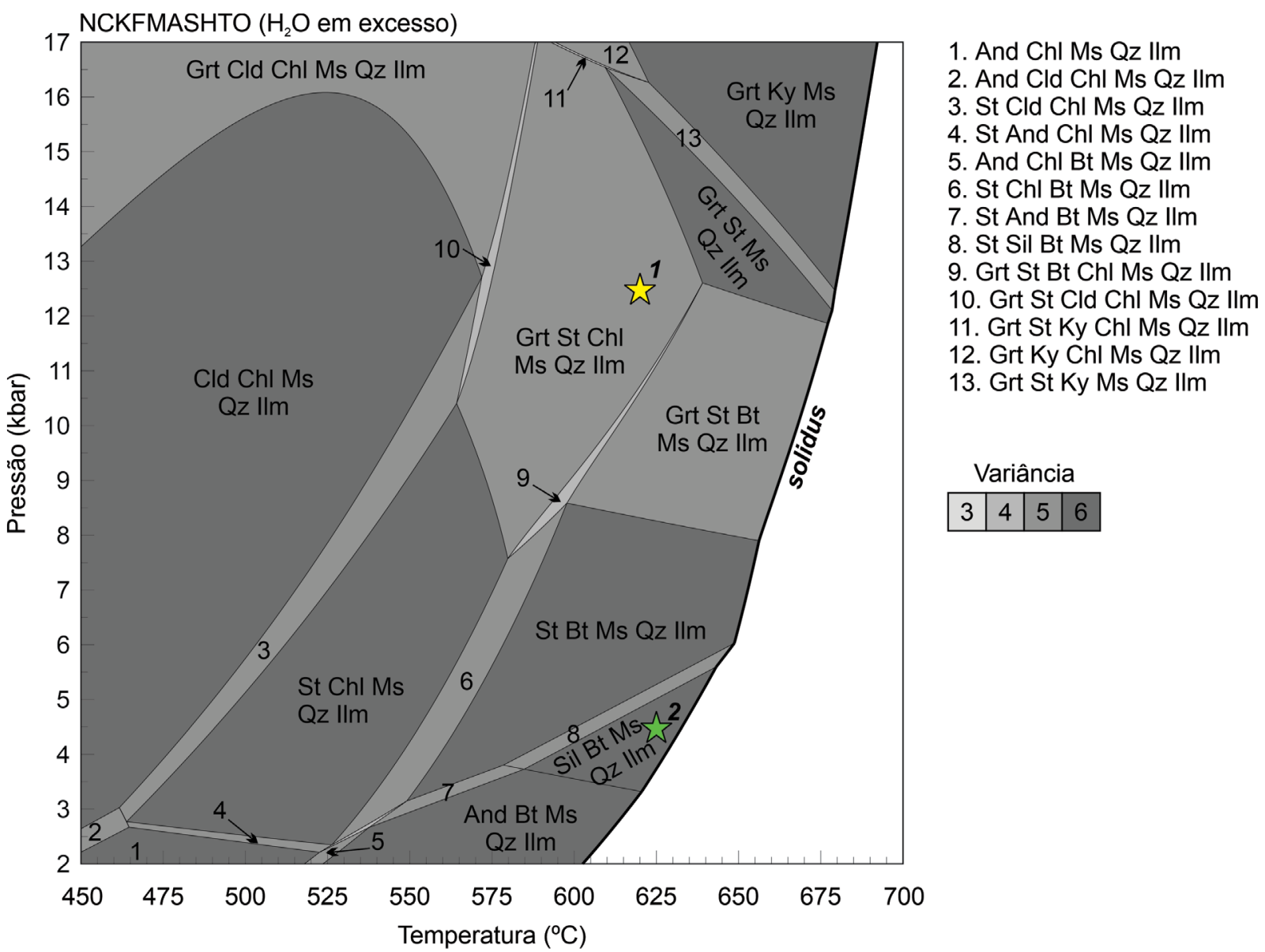

Figura 10. Pseudosseção P-T calculada no sistema NCKFMASHTO para a amostra SC-07. $\mathrm{SiO}_{2}(70,14), \mathrm{Al}_{2} \mathrm{O}_{3}(16,18)$, $\mathrm{FeO}(5,5), \mathrm{MgO}(2,46), \mathrm{CaO}(0,05), \mathrm{K}_{2} \mathrm{O}(3,13), \mathrm{Na}_{2} \mathrm{O}(1,16), \mathrm{TiO}_{2}(0,91)$ e $\mathrm{O}(0,36)$, em \% molar. As associações minerais indicadas pelas estrelas amarela (1) e verde (2) são exemplos para serem comparados com a variação do sistema químico modelo (ver Tabela 1).

Tabela 1. Dois exemplos de associações vistas em cada um dos sistemas químicos adotados nas Figuras de 9 a 11.

\begin{tabular}{|c|c|c|c|c|}
\hline Sistema químico & $1-620^{\circ} \mathrm{C}, 12,5 \mathrm{kbar}$ & $\mathbf{F}$ & $2-625^{\circ} \mathrm{C}, 4,5 \mathrm{kbar}$ & $\mathrm{F}$ \\
\hline KFMASH & $\mathrm{Grt}+\mathrm{St}+\mathrm{Ms}+\mathrm{Qz}$ & 3 & $\mathrm{Sil}+\mathrm{Bt}+\mathrm{Ms}+\mathrm{Qz}$ & 3 \\
\hline NCKFMASHTO & $\mathrm{Grt}+\mathrm{St}+\mathrm{Chl}+\mathrm{Ms}+\| \mathrm{m}+\mathrm{Qz}$ & 5 & $\mathrm{Sil}+\mathrm{Bt}+\mathrm{Ms}+\| \mathrm{m}+\mathrm{Qz}$ & 6 \\
\hline MnNCKFMASHTO & $\mathrm{Grt}+\mathrm{St}+\mathrm{Chl}+\mathrm{Ms}+\| \mathrm{m}+\mathrm{Qz}$ & 6 & $\mathrm{Grt}+\mathrm{Sil}+\mathrm{Bt}+\mathrm{Ms}+\| \mathrm{m}+\mathrm{Qz}$ & 6 \\
\hline
\end{tabular}

KFMASH, a pseudosseção no sistema NCKFMASHTO não considera cianita como fase aluminosa para condições de menor temperatura. A cianita é estável apenas a partir da quebra da estaurolita e não via consumo da clorita, quando costuma ocorrer na chamada "zona da cianita" junto com biotita. A rocha tem baixo teor de $\mathrm{CaO}$ e, portanto, não estabiliza nem plagioclásio, nem margarita, com $\mathrm{CaO}$ sendo totalmente incorporado à granada.

Rochas metapelíticas apresentam baixos conteúdos de $\mathrm{MnO}$. No entanto, esse pode ter efeitos significativos no equilíbrio das associações minerais, especialmente daquelas que envolvem granada, em razão de seu intenso particionamento de $\mathrm{MnO}$. Por exemplo, o campo de estabilidade da associação granada + biotita + clorita + quartzo $+\mathrm{H}_{2} \mathrm{O}$, que é uma das mais comuns e importantes no metamorfismo de fácies xisto verde e até, em algumas composições, da fácies anfibolito, é muito restrito no diagrama KFMASH (Figura 7). O que ocorre, na verdade, é que a simples adição de um componente extra muda os limites das reações, de modo que a granada incorpora a maior parte do $\mathrm{MnO}$ da rocha e terá seus campos de estabilidade expandidos (Spear, 1993), sobretudo para associações minerais 
formadas sob condições de fácies xisto verde a anfibolito (Figuras 10 e 11), até a transição para a fácies granulito de baixa a média pressão, mas são menos intensos em condições de maior pressão e temperatura, já que granada é uma fase comum na maioria dos metapelitos formados nessas condições (White et al., 2014b).

Para completar a comparação, pode-se adicionar $\mathrm{MnO}$ e investigar os efeitos na topologia e na estabilidade das fases. A vantagem do sistema MnNCKFMASHTO é que ele incorpora os efeitos de todos os componentes discutidos anteriormente no cálculo de pseudosseções para rochas metapelíticas (White et al., 2014b), gerando a representação, em tese, mais próxima do sistema natural, levando-se em consideração os modelos de atividade e os dados termodinâmicos atualmente disponíveis. Em termos de topologia, as pseudosseções nos sistemas NCKFMASHTO e MnNCKFMASHTO - Figuras 10 e 11, respectivamente - , embora mostrem diferentes graus de liberdade, são muito semelhantes, sendo suas particularidades controladas exclusivamente pelos campos de estabilidade de associações envolvendo granada. A adição de $\mathrm{MnO}$, como apontado por Spear e Cheney (1989), resulta na expansão dos campos de estabilidade da granada para pressões e temperaturas mais baixas. No entanto, há pouca influência na estabilidade das demais fases, o que é condizente com o que é observado na natureza (White et al., 2014b).

Mesmo com as complexidades advindas da adição de componentes extras, as topologias de subsistemas mais simples se mantêm (White et al., 2014a) sem grandes alterações. A construção de diagramas no sistema NCKFMASHTO, por exemplo, sobrepõe três subsistemas mais "simples" para estabelecer as relações entre suas fases, KFMASH, e suas relações com $\mathrm{Fe}_{2} \mathrm{O}_{3}-\mathrm{FeO}-\mathrm{TiO}_{2}$ e $\mathrm{CaO}-\mathrm{Na}_{2} \mathrm{O}-\mathrm{K}_{2} \mathrm{O}$. As interdependências surgem quando minerais ferromagnesianos incorporam $\mathrm{Fe}_{2} \mathrm{O}_{3}$ e $\mathrm{TiO}_{2}$, estabelecendo a conexão

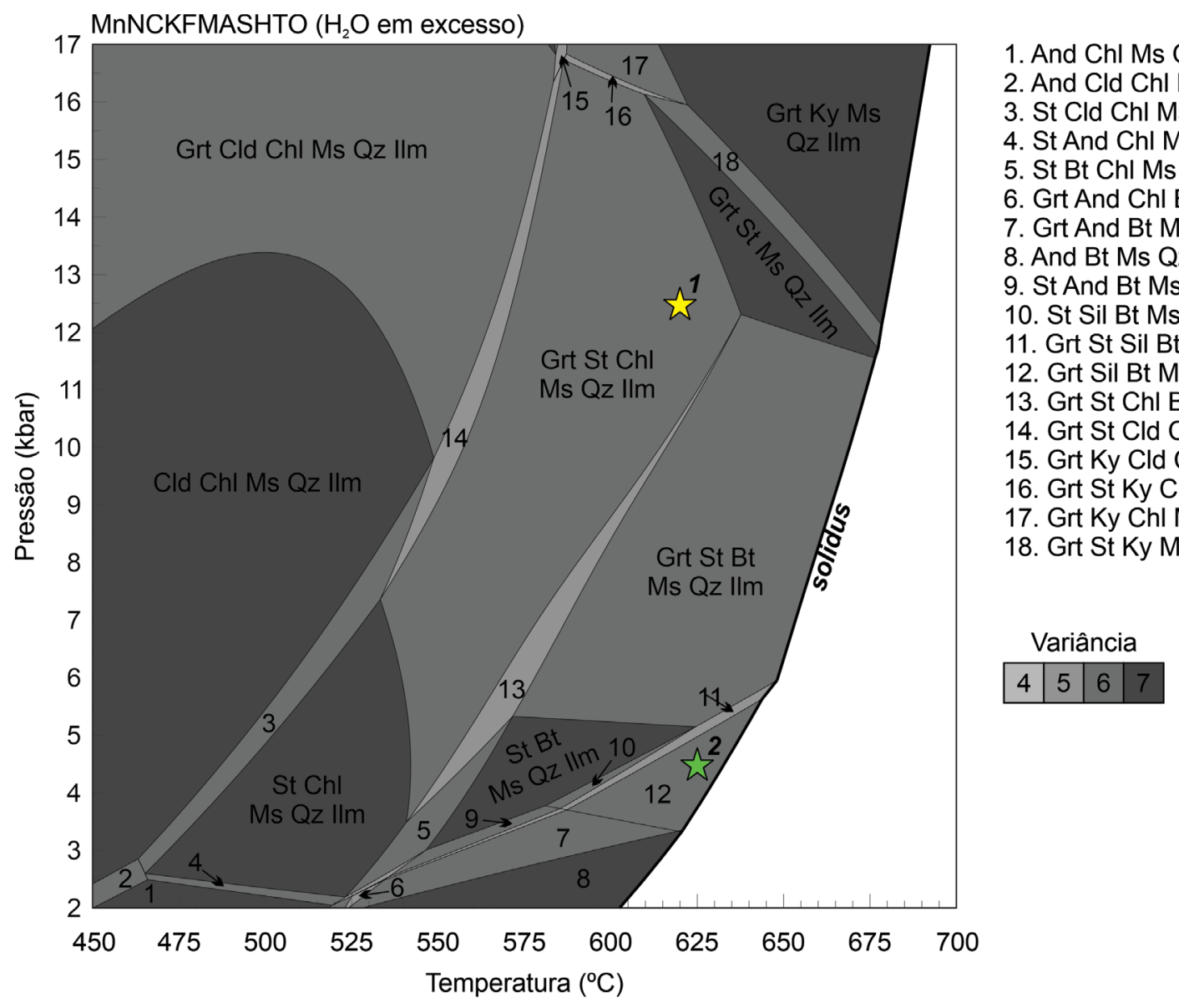

Figura 11. Pseudosseção calculada no sistema MnNCKFMASHTO. $\mathrm{SiO}_{2}(70,14), \mathrm{Al}_{2} \mathrm{O}_{3}(16,18), \mathrm{FeO}(5,5), \mathrm{MgO}(2,46)$, $\mathrm{MnO}(0,11), \mathrm{CaO}(0,05), \mathrm{K}_{2} \mathrm{O}(3,13), \mathrm{Na}_{2} \mathrm{O}(1,16), \mathrm{TiO}_{2}(0,91)$ e $\mathrm{O}(0,36)$, em \% molar. As associações minerais indicadas pelas estrelas amarela (1) e verde (2) são exemplos para serem comparados com a variação do sistema químico modelo (ver Tabela 1). 
entre os sistemas KFMASH e $\mathrm{Fe}_{2} \mathrm{O}_{3}-\mathrm{FeO}-\mathrm{TiO}_{2}$ ou quando a rocha tem plagioclásio, o que também permite a entrada de $\mathrm{CaO}$ na granada e $\mathrm{Na}_{2} \mathrm{O}$ e $\mathrm{CaO}$ na mica branca (White et al., 2014a).

\section{CONSIDERAÇÕES FINAIS}

O modelamento termodinâmico tem se tornado cada vez mais importante, já que suas aplicações são variadas e estão nas aplicações mais modernas da Petrologia Metamórfica, sobretudo com o avanço de estudos voltados para a Petrocronologia. Nem tudo é possível de ser compreendido ou está resolvido nesse campo, principalmente em relação aos modelos de atividade das soluções sólidas mais complexas, por exemplo, de minerais do grupo dos anfibólios, das cloritas, da safirina, entre outros. Apesar disso, ainda existe uma lacuna entre a bibliografia voltada para os conhecimentos básicos de Petrologia e o material base disponibilizado pelos grupos de pesquisa que produzem os softwares, que, em geral, ensinam apenas especificidades do uso de cada um.

Esperam os autores que esta contribuição preencha parte dessa lacuna. Em parte, pois aqui foram discutidos apenas os aspectos fundamentais de uma pseudosseção para um metapelito de composição simples, sem adentrar nas particularidades sobre as quantidades de $\mathrm{H}_{2} \mathrm{O}$ e $\mathrm{Fe}_{2} \mathrm{O}_{3}$ utilizadas. Apesar de o presente artigo apresentar as diretrizes básicas das pseudosseções e fazer uma pequena comparação sobre a variação dos sistemas químicos na topologia das pseudosseções de rochas metapelíticas, existem trabalhos em que outros problemas são abordados, tais como o metamorfismo de rochas máficas (e.g. Santos et al., 2019, 2021) e questões relacionadas à fusão parcial (e.g. Pavan et al., 2021a, 2021b).

Os três softwares citados (Anexo 1) aqui podem facilmente ser encontrados na internet, em conjunto com os bancos de dados termodinâmicos e os modelos de atividade-composição, já em formatos de arquivos compatíveis com cada software, além de tutoriais e informações adicionais, que auxiliam na construção de diagramas de fase em geral. É essencial consultar o material de referência de cada software e se habituar a seu uso, de forma que os conhecimentos básicos em termodinâmica e petrologia sejam empregados como um "controle de qualidade", necessário para evitar a produção de modelos falhos ou irreais.

Por fim, cumpre ressaltar que o trabalho anterior ao modelamento, especialmente a petrografia, não pode ser negligenciado, pois é isso que dará embasamento para um bom modelamento, e fará com que os diagramas calculados sejam não só diagramas termodinamicamente corretos, mas que tenham também significados geológico e petrológico importantes.

\section{AGRADECIMENTOS}

$\mathrm{O}$ artigo foi desenvolvido com a ajuda financeira da Fundação de Amparo à Pesquisa do Estado de São Paulo - FAPESP (16/22627-3). Os autores agradecem à Coordenação de Aperfeiçoamento de Pessoal de Nível Superior (CAPES) o apoio financeiro. RMG foi bolsista de doutorado da CAPES, CAS foi bolsista de doutorado do Conselho Nacional de Desenvolvimento Científico e Tecnológico (CNPq) e RM tem Bolsa de Produtividade do CNPq (305720/2020-1). Os autores agradecem também os comentários de George Luiz Luvizotto e de um revisor anônimo, que em muito enriqueceram a qualidade e a clareza do texto.

\section{REFERÊNCIAS}

Atkins, P., Paula, J. (2018). Físico-química. Rio de Janeiro: LTC, $512 \mathrm{p}$.

Ball, D. W. (2005). Físico-química. São Paulo: Thomson, 877 p.

Barrow, G. (1893). On an intrusion of muscovite-biotite gneiss in the south-eastern highlands of Scotland, and its accompanying metamorphism. Quarterly Journal of the Geological Society, 49, 330-358. https://doi.org/10.1144/ GSL.JGS.1893.049.01-04.52

Barrow, G. (1912). On the geology of lower dee-side and the southern Highland border. Proceedings of the Geologists' Association, 23, 274-290. Disponível em: https://dokumen.tips/documents/on-the-geology-of-lowerdee-side-and-the-southern-highland-border.html. Acesso em: 19 nov. 2021.

Berman, R. G. (1988). Internally-consistent thermodynamic data for minerals in the system $\mathrm{Na}_{2} \mathrm{O}-\mathrm{K}_{2} \mathrm{O}-\mathrm{CaO}-\mathrm{MgO}-\mathrm{FeO}-$ $\mathrm{Fe}_{2} \mathrm{O}_{3}-\mathrm{Al}_{2} \mathrm{O}_{3}-\mathrm{SiO}_{2}-\mathrm{TiO}_{2}-\mathrm{H}_{2} \mathrm{O}-\mathrm{CO}_{2}$. Journal of Petrology, 29(2), 445-522. https://doi.org/10.1093/petrology/29.2.445

Brown, M., Johnson, T. (2018). Secular change in metamorphism and the onset of global plate tectonics. American Mineralogist, 103(2), 181-196. https://doi. org/10.2138/am-2018-6166

Bucher, K., Grapes, R. (2011). Petrogenesis of metamorphic rocks. Heidelberg: Springer-Verlag, 428 p. https://doi. org/10.1007/978-3-540-74169-5

Candia, M. A. F., Szabó, G. A. J., Del Lama, E. A. (2003). Petrologia metamórfica: fundamentos para a interpretação de diagramas de fase. São Paulo: EDUSP, 190 p. 
Carlson, W. D. (2002). Scales of disequilibrium and rates of equilibration during metamorphism. American Mineralogist, 87(2-3), 185-204. https://doi.org/10.2138/am-2002-2-301

Carlson, W. D., Pattison, D. R. M., Caddick, M. J. (2015). Beyond the equilibrium paradigm: how consideration of kinetics enhances metamorphic interpretation. American Mineralogist, 100(8-9), 1659-1667. https://doi.org/10.2138/ am-2015-5097

Connolly, J. A. D. (1990). Multivariable phase-diagrams-an algorithm based on generalized thermodynamics. American Journal of Science, 290(6), 666-718. https://doi.org/10.2475/ ajs.290.6.666

Connolly, J. A. D., Kerrick, D. M. (1987). An algorithm and computer program for calculating composition phase diagrams. Calphad, 11(1), 1-55. https://doi. org/10.1016/0364-5916(87)90018-6

de Capitani, C., Brown, T. H. (1987). The computation of chemical equilibrium in complex systems containing non-ideal solutions. Geochimica et Cosmochimica Acta, 51(10), 2639-2652. https://doi. org/10.1016/0016-7037(87)90145-1

de Capitani, C., Petrakakis, K. (2010). The computation of equilibrium assemblage diagrams with Theriak/Domino software. American Mineralogist, 95(7), 1006-1016. https:// doi.org/10.2138/am.2010.3354

Diener, J. F. A., Powell, R. (2010). Influence of ferric iron on the stability of mineral assemblages: Journal of Metamorphic Geology, 28(6), 599-613. https://doi. org/10.1111/j.1525-1314.2010.00880.x

Diener, J. F. A., Powell, R. (2012). Revised activitycomposition models for clinopyroxene and amphibole. Journal of Metamorphic Geology, 30(2), 131-142. https:// doi.org/10.1111/j.1525-1314.2011.00959.x

Duesterhoeft, E. (2017). BED92.v1 - Theriak-Domino Database. https://doi.org/10.13140/RG.2.2.10285.69609

Duesterhoeft, E., Lanari, P. (2020). Iterative thermodynamic modelling-Part 1: A theoretical scoring technique and a computer program (Bingo-Antidote). Journal of Metamorphic Geology, 38(5), 527-551. https://doi. org/10.1111/jmg.12538

Eskola, P. (1939). Die enstehung der Gesteine. Berlin: SpringerVerlag. https://doi.org/10.1007/978-3-642-86244-1
Fumes, R. A., Luvizotto, G., Moraes, R., Lanari, P., Valeriano, C., Zack, T., Caddick, M., Simões, L. S. (2021). Petrochronology of high-pressure granulite facies rocks from Southern Brasília Orogen, SE Brazil: combining quantitative compositional mapping, single-element thermometry and geochronology. Journal of Metamorphic Geology. https:// doi.org/10.1111/jmg.12637

Green, E. C. R., White, R. W., Diener, J. F. A., Powell, R., Holland, T. J. B., Palin, R. M. (2016). Activity-composition relations for the calculation of partial melting equilibria in metabasic rocks. Journal of Metamorphic Geology, 34(9), 845-869. https://doi.org/10.1111/jmg.12211

Helgeson, H. C., Delany, J. M., Nesbitt, H. W., Bird, D. K. (1978). Summary and critique of the thermodynamic properties of rock-forming minerals. American Journal of Science, 278A, 1-229.

Hensen, B. J. (1971). Theoretical phase relations involving cordierite and garnet in the system $\mathrm{MgO}-\mathrm{FeO}-\mathrm{Al}_{2} \mathrm{O}_{3}-\mathrm{SiO}_{2}$. Contribution to Mineralogy and Petrology, 33, 191-214. https://doi.org/10.1007/BF00374063

Holland, T. J. B., Powell, R. (1985). An internally consistent thermodynamic dataset with uncertainties and correlations: 2. Data and results. Journal of Metamorphic Geology, 3(4), 343-370. https://doi.org/10.1111/j.1525-1314.1985. tb00325.x

Holland, T. J. B., Powell, R. (1998). An internally consistent thermodynamic dataset for phases of petrological interest. Journal of Metamorphic Geology, 16(3), 309-344. https:// doi.org/10.1111/j.1525-1314.1998.00140.x

Holland, T. J. B., Powell, R. (2011). An improved and extended internally consistent thermodynamic dataset for phases of petrological interest, involving a new equation of state for solids. Journal of Metamorphic Geology, 29(3), 333-383. https://doi. org/10.1111/j.1525-1314.2010.00923.x

Joesten, R. (1977). Evolution of mineral assemblage zoning in diffusion metasomatism. Geochimica et Cosmochimica Acta, 41(5), 649-670. https://doi. org/10.1016/0016-7037(77)90303-9

Lanari, P., Duesterhoeft, E. (2019). Modeling metamorphic rocks using equilibrium thermodynamics and internally consistent databases: past achievements, problems and perspectives. Journal of Petrology, 60(1), 19-56. https:// doi.org/10.1093/petrology/egy 105 
Lanari, P., Engi, M. (2017). Local bulk composition effects on metamorphic mineral assemblages. Reviews in Mineralogy and Geochemistry, 83, 55-102. https://doi. org/10.1515/9783110561890-004

López-Carmona, A., Pitra, P., Abati, J. (2013). Blueschistfacies metapelites from the Malpica-Tui Unit (NW Iberian Massif): phase equilibria modelling and $\mathrm{H}_{2} \mathrm{O}$ and $\mathrm{Fe}_{2} \mathrm{O}_{3}$ influence in high-pressure assemblages. Journal of Metamorphic Geology, 31(3), 263-280. https://doi. org/10.1111/jmg.12018

Mirwald, P. W., Massonne, H. J. (1980). The low-high quartz and quartz-coesite transition to $40 \mathrm{kbar}$ between 600 and $1600^{\circ} \mathrm{C}$ and some reconnaissance data on the effect of $\mathrm{NaAlO}$, component on the low quartz-coesite transition. Journal of Geophysical Research, 85(B12), 6983-6990. https://doi.org/10.1029/JB085iB12p06983

Motta, R. G., Fitzsimons, I. C. W., Moraes, R., Johnson, T. E., Schuindt, S., Benetti, B. Y. (2021). Recovering P-T-t paths from ultra-high temperature (UHT) felsic orthogneiss: an example from the Southern Brasília Orogen, Brazil. Precambrian Research, 359, 106222. https://doi.org/10.1016/j. precamres.2021.106222

Palin, R. M., Weller, O. M., Waters, D. J., Dyck, B. (2016). Quantifying geological uncertainty in metamorphic phase equilibria modelling; a Monte Carlo assessment and implications for tectonic interpretations. Geoscience Frontiers, 7(4), 591-607. https://doi.org/10.1016/j.gsf.2015.08.005

Pavan, M. (2010). Modelamento metamórfico de rochas das fácies xisto-verde e anfibolito com o uso de pseudosseções: exemplo das rochas da klippe Carrancas, sul de Minas Gerais. Dissertação (Mestrado). São Paulo: Universidade de São Paulo, 147 p. https://doi.org/10.11606/D.44.2010. tde-06052010-145012

Pavan, M., Moraes, R., Sawyer, E. W. (2021a). Changes in the composition of anatectic melt and its complementary residue by forward-modelling using THERMOCALC. Lithos, 396397, 106220. https://doi.org/10.1016/j.lithos.2021.106220

Pavan, M., Sawyer, E. W., Moraes, R., Faleiros, F. M. (2021b). Partial melting of granodiorite, a common igneous rock: insights from Ediacaran granulite-facies metamorphism in the Southern Brazil. Journal of Petrology, 62(7), egab028. https://doi.org/10.1093/petrology/egab028

Philpotts, A. R., Ague, J. J. (2009). Principles of igneous and metamorphic geology. Nova York: Cambridge University Press, $667 \mathrm{p}$.
Powell, R. (1978). Equilibrium thermodynamics in petrology. Londres: Harper \& Row, 284 p.

Powell, R., Guiraud, M., White, R. W. (2005). Truth and beauty in metamorphic phase-equilibria: Conjugate variables and phase diagrams. The Canadian Mineralogist, 43(1), 21-33. https://doi.org/10.2113/gscanmin.43.1.21

Powell, R., Holland, T. J. B. (1988). An internally consistent thermodynamic dataset with uncertainties and correlations: application methods, worked examples and a computer program. Journal of Metamorphic Geology, 6(2), 173-204. https://doi.org/10.1111/j.1525-1314.1988.tb00415.x

Powell, R., Holland, T. J. B. (1990). Calculated mineral equilibria in the pelite system, $\mathrm{KFMASH}\left(\mathrm{K}_{2} \mathrm{O}-\mathrm{FeO}-\right.$ $\mathrm{MgO}-\mathrm{Al}_{2} \mathrm{O}_{3}-\mathrm{SiO}_{2}-\mathrm{H}_{2} \mathrm{O}$ ). American Mineralogist, 75(34), 367-380.

Powell, R., Holland, T. J. B. (1993). On the formulation of simple mixing models for complex phases. American Mineralogist, 78(11-12), 1174-1180. Disponível em: http://pubs.geoscienceworld.org/msa/ammin/articlepdf/78/11-12/1174/4218476/am78_1174.pdf. Acesso em: 19 nov. 2021.

Powell, R., Holland, T. (2008). On thermobarometry. Journal of Metamorphic Geology, 26(2), 155-179. https:// doi.org/10.1111/j.1525-1314.2007.00756.x

Powell, R., Holland, T., Worley, B. (1998). Calculating phase diagrams involving solid solutions via non-linear equations, with examples using THERMOCALC. Journal of Metamorphic Geology, 16(4), 577-588. https://doi. org/10.1111/j.1525-1314.1998.00157.x

Powell, R., White, R. W., Kelsey, D., Diener, J. (2006). THERMOCALC Short Course. São Paulo. Disponível em: https://hpxeosandthermocalc.org/the-thermocalc-software/ thermocalc-help/. Acesso em: 19 nov. 2021.

Proyer, A., Dachs, E., McCammon, C. (2004). Pitfalls in geothermobarometry of eclogites: $\mathrm{Fe}^{3+}$ and changes in the mineral chemistry of omphacite at ultrahigh pressures. Contributions to Mineralogy and Petrology, 147(3), 305318. https://doi.org/10.1007/s00410-004-0554-6

Reno, B. L., Brown, M., Kobayashi, K., Nakamura, E., Piccoli, P. M., Trouw, R. A. J. (2009). Eclogite-high-pressure granulite metamorphism records early collision in West Gondwana: new data from the Southern Brasília Belt, Brazil. Journal of the Geological Society, 166(6), 1013-1032. https://doi. org/10.1144/0016-76492008-140 
Santos, A. C., Moraes, R., Szabó, G. A. J. (2019). A comparison between pseudosections for metamafic rocks using THERMOCALC and experimental and independent thermobarometric data. Lithos, 340-341, 108-123. https:// doi.org/10.1016/j.lithos.2019.04.024

Santos, C., White, R. W., Moraes, R., Szabó, G. A. J. (2021). The gabbro to amphibolite transition along a hydrationdeformation front. Journal of Metamorphic Geology, 39(4), 417-442. https://doi.org/10.1111/jmg.12582

Spear, F. S. (1993). Metamorphic phase equilibria and pressure-temperature-time paths. Washington, D.C.: Mineralogical Society of America, 799 p.

Spear, F. S., Cheney, J. T. (1989). A petrogenetic grid for politic schists in the system $\mathrm{SiO}_{2}-\mathrm{Al}_{2} \mathrm{O}_{3}-\mathrm{FeO}-\mathrm{MgO}-\mathrm{K}_{2} \mathrm{O}-$ $\mathrm{H}_{2} \mathrm{O}$. Contributions to Mineralogy and Petrology, 101, 149164. https://doi.org/10.1007/BF00375302

Spear, F. S., Pattison, D. R. M, Cheney, J. T. (2016). The metamorphosis of metamorphic petrology. Geological Society of America Special Paper, 523. https://doi. org/10.1130/2016.2523(02)

Štipska, P., Powell, R., White, R. W., Baldwin, J. A. (2010). Using calculated chemical potential relationships to account for coronas around kyanite: an example from the Bohemian Massif. Journal of Metamorphic Geology, 28(1), 97-116. https://doi.org/10.1111/j.1525-1314.2009.00857.x

Stüwe, K. (1997). Effective bulk composition changes due to cooling: a model predicting complexities in retrograde reaction textures. Contributions to Mineralogy and Petrology, 129, 43-52. https://doi.org/10.1007/s004100050322

Tedeschi, M., Lanari, P., Rubatto, D., Pedrosa-Soares, A., Hermann, J., Dussin, I., Pinheiro, M. A. P., Bouvier, A. S., Baumgartner, L. (2017). Reconstruction of multiple P-T-t stages from retrogressed mafic rocks: Subduction versus collision in the Southern Brasília Orogen (SE Brazil). Lithos, 294-295, 283-303. https://doi.org/10.1016/j.lithos.2017.09.025

Thompson, J. B. Jr. (1957). The graphical analysis of mineral assemblages in pelitic schists. American Mineralogist, 42(1112), 842-858. Disponível em: http://pubs.geoscienceworld. org/msa/ammin/article-pdf/42/11-12/842/4247296/am-1957842.pdf. Acesso em: 19 nov. 2021.

Trommsdorff, V., Evans, B. W. (1972). Progressive metamorphism of antigorite schist in the Bergell tonalite aureole (Italy). American Journal of Science, 272(5), 423437. https://doi.org/10.2475/ajs.272.5.423
Trouw, R. A. J., Ribeiro, A., Paciullo, F. V. P. (1983). Geologia estrutural dos Grupos São João Del Rei, Carrancas e Andrelândia, sul de Minas Gerais. Anais da Academia Brasileira de Ciências, 55, 71-85.

Wernert, P., Schulmann, K., Chopin, F., Štipska, P., Bosch, D., El Houicha, M. (2016). Tectonometamorphic evolution of an intracontinental orogeny inferred from $P-T-\mathrm{t}-\mathrm{d}$ paths of the metapelites from the Rehamna massif (Morocco). Journal of Metamorphic Geology, 34(9), 917-940. https:// doi.org/10.1111/jmg.12214

White, R. W., Powell, R. (2010). Retrograde melt-residue interaction and the formation of near-anhydrous leucosomes in migmatites, Journal of Metamorphic Geology, 28(6), 579-597. https://doi.org/10.1111/j.1525-1314.2010.00881.x

White, R. W., Powell, R., Baldwin, J. A. (2008). Calculated phase equilibria involving chemical potentials to investigate the textural evolution of metamorphic rocks. Journal of Metamorphic Geology, 26(2), 181-198. https://doi. org/10.1111/j.1525-1314.2008.00764.x

White, R. W., Powell, R., Clarke, G. L. (2002). The interpretation of reaction textures in Fe-rich metapelitic granulites of the Musgrave Block, central Australia: constraints from mineral equilibria calculations in the system $\mathrm{K}_{2} \mathrm{O}-\mathrm{FeO}-\mathrm{MgO}-\mathrm{Al}_{2} \mathrm{O}_{3}-$ $\mathrm{H}_{2} \mathrm{O}-\mathrm{Fe}_{2} \mathrm{O}_{3}$. Journal of Metamorphic Geology, 20(1), 41-55. https://doi.org/10.1046/j.0263-4929.2001.00349.x

White, R. W., Powell, R., Holland, T. J. B. (2007). Progress relating to calculation of partial melting equilibria for metapelites. Journal of Metamorphic Geology, 25, 511-527. https://doi.org/10.1111/j.1525-1314.2007.00711.x

White, R. W., Powell, R., Holland, T. J. B., Johnson, T. E., Green, E. C. R. (2014a). New mineral activity-composition relations for thermodynamic calculations in metapelitic systems. Journal of Metamorphic Geology, 32(3), 261-286. https://doi.org/10.1111/jmg.12071

White, R. W., Powell, R., Holland, T. J. B., Worley, B. A. (2000). The effect of $\mathrm{TiO}_{2}$ and $\mathrm{Fe}_{2} \mathrm{O}_{3}$ on metapelitic assemblages at greenschist and amphibolite facies conditions: Mineral equilibria calculations in the system $\mathrm{K}_{2} \mathrm{O}-\mathrm{FeO}-\mathrm{MgO}-\mathrm{Al}_{2} \mathrm{O}_{3}-$ $\mathrm{SiO}_{2}-\mathrm{H}_{2} \mathrm{O}-\mathrm{TiO}_{2}-\mathrm{Fe}_{2} \mathrm{O}_{3}$. Journal of Metamorphic Geology, 18(5), 497-511. https://doi.org/10.1046/j.1525-1314.2000.00269.x

White, R. W., Powell, R., Johnson, T. E. (2014b). The effect of $\mathrm{Mn}$ on mineral stability in metapelites revisited: New a-x relations for manganese-bearing minerals: Journal of Metamorphic Geology, 32(8), 809-828. https://doi. org/10.1111/jmg.12095 
Whitney, D. L., Evans, B. W. (2010). Abbreviations for names of rock-forming minerals. American Mineralogist, 95(1), 185-187. https://doi.org/10.2138/am.2010.3371

Will, T. M. (1998). Phase equilibria in metamorphic rocks: thermodynamic background and petrological applications. Berlin: Springer-Verlag. 315 p. https://doi.org/10.1007/BFb0117723
Zen, E-a. (1966). Construction of pressure temperature diagrams for multicomponent systems after the method of Schreinemakers - a geometric approach: United States Geological Survey Bulletin, v. 1225. 68 p. Disponível em: https://pubs.usgs.gov/bul/1225/report.pdf. Acesso em: 19 nov. 2021.

\section{Anexo 1}

Perplex: http://www.perplex.ethz.ch/)

Theriak: https://titan.minpet.unibas.ch/minpet/theriak/theruser.html, http://www.rocks.uni-kiel.de/theriakd/html/down_en.html THERMOCALC: https://hpxeosandthermocalc.org/ 